\title{
Mechanisms Determining the Winter Atmospheric Response to the Atlantic Overturning Circulation $\mathscr{O}$
}

\author{
G. Gastineau, B. L'Hévéder, F. Codron, And C. Frankignoul \\ Sorbonne Universités, UPMC/CNRS/IRD/MNHN, LOCEAN/IPSL, Paris, France
}

(Manuscript received 6 May 2015, in final form 23 February 2016)

\begin{abstract}
In climate models, an intensification of the Atlantic meridional overturning circulation (AMOC) precedes a warming in the North Atlantic subpolar basin by a few years. In the IPSL-CM5A-LR model, this warming may explain the atmospheric response to the AMOC observed in winter, which resembles a negative phase of the North Atlantic Oscillation (NAO). To firmly establish the causality links between the ocean and the atmosphere and illustrate the underlying mechanisms in this model, ensembles of atmosphere-only simulations are conducted, prescribing the SST and sea ice anomalies that follow an AMOC intensification. In late winter, the North Atlantic SST and sea ice anomalies drive atmospheric circulation anomalies similar to those found in the coupled model. Simulations only driven by the SST anomalies related to the AMOC show that the largest oceanic influence is due to the warm subpolar SST anomaly, which enhances the oceanic heat release and decreases the lower-tropospheric baroclinicity in the region of maximum eddy growth, resulting in a weaker meridional eddy heat flux in the atmosphere. The transient eddy feedback leads to a negative NAO-like response. An AMOC intensification is also followed by less sea ice over the Labrador Sea and more sea ice over the Nordic seas. The simulations with full boundary forcing suggest that such anomalies act to strengthen both the poleward momentum flux and the upward heat flux into the polar stratosphere and lead to a stratospheric warming, which then reinforces the negative NAO signal in late winter.
\end{abstract}

\section{Introduction}

Observational data from the instrumental period and paleoproxies show a large decadal-to-multidecadal variability in the North Atlantic Ocean (Kerr 2000; Kilbourne et al. 2008; Knudsen et al. 2011). The main mode of sea surface temperature (SST) variability is a basin-wide warming or cooling, with the largest SST anomalies over the North Atlantic subpolar basin, commonly referred to as the Atlantic multidecadal oscillation (AMO). Coupled models also exhibit such variability, which was shown to be mostly due to the variability of the Atlantic overturning meridional circulation (AMOC; Knight et al. 2005), although external forcing might also

Supplemental information related to this paper is available at the Journals Online website: http://dx.doi.org/10.1175/ JCLI-D-15-0326.s1.

Corresponding author address: Dr. Guillaume Gastineau, Sorbonne Universités, UPMC/CNRS/IRD/MNHN, LOCEAN/IPSL, 4 place Jussieu, 75005 Paris, France.

E-mail: guillaume.gastineau@upmc.fr have an influence in historical simulations and global warming runs (Otterå et al. 2010). Stochastic atmospheric forcing may also have an influence on SST that projects onto the AMO (Clement et al. 2015).

In observations, the AMO influences a wide spectrum of climate phenomena. In particular, the AMO modifies the precipitation over the tropical Atlantic region (Enfield et al. 2001; McCabe et al. 2004; Knight et al. 2006; Mohino et al. 2011) and the hurricane frequency, mostly notably during boreal summer (Goldenberg et al. 2001; Zhang and Delworth 2006; Chylek and Lesins 2008; Dunstone et al. 2011). In the midlatitudes, the AMO was shown to modify the precipitation and temperature over the surrounding region both in boreal summer (Sutton and Hodson 2005; Seager et al. 2008) and winter (Ting et al. 2011; Ionita et al. 2012; Ting et al. 2014). In addition, a warm AMO phase may favor a negative phase of the North Atlantic Oscillation during the cold season, and thus enhance the frequency of extreme cold temperatures in winter over Europe (Ting et al. 2014; Omrani et al. 2014; Peings and Magnusdottir 2014; Gastineau and Frankignoul 2015). The interactions between NAO and North Atlantic SST may also explain the important SST 
cooling in the subpolar North Atlantic Ocean observed in the 1960s and 1970s (Hodson et al. 2014).

A deeper understanding of the AMOC climate impacts, and the processes involved are of great interest, as the AMOC has a large persistence and is potentially predicable up to a decade in advance (Keenlyside et al. 2008; Msadek et al. 2010; Matei et al. 2012). Unfortunately, observations of the AMOC only began in 2005 (Smeed et al. 2014), so that the observational record is too limited to clearly establish the AMOC climate impacts. Therefore, the mechanisms leading to the winter atmospheric response to the AMOC are mainly explored using modeling.

In many climate models, the AMOC has a lagged influence that produces an SST anomaly pattern similar to the observed AMO (Delworth and Mann 2000; Latif et al. 2004; Medhaug and Furevik 2011; Zhang and Wang; 2013). An intensification of the AMOC main mode of variability is followed a few years later by a surface warming of the subpolar North Atlantic and, in most cases, cooling in the Gulf Stream region. Using six climate models, Gastineau and Frankignoul (2012, hereafter GF12) showed that the AMOC is also followed during winter by dipolar atmospheric pressure anomalies over the Euro-Atlantic sector corresponding roughly to a negative NAO phase, in phase with the subpolar SST warming. The mechanism suggested in GF12 is that warm subpolar SST anomalies lead to modifications of the lower-tropospheric baroclinicity and storm track, which evolves into a negative NAO pattern through eddy-mean flow interactions. However, many other mechanisms can also explain the NAO response to the AMOC. First, the subpolar warming in climate models is often accompanied by a warming of the tropical North Atlantic SST and a northward shift of the ITCZ, which could force a stationary wave response in the atmosphere over the North Atlantic sector (Hodson et al. 2010). Second, a weakening of the polar vortex in response to a warming of the North Atlantic SST precedes the winter NAO in the troposphere by 1 month, which acts as a positive feedback on the NAO (Omrani et al. 2014). Last, the AMOC variability is also accompanied by sea ice changes (Mahajan et al. 2011; GF12; Allison et al. 2015; Zhang 2015). The sea ice variability has a major influence on the surface heat fluxes and it may also influence the North Atlantic Oscillation (Deser et al. 2007; Strong et al. 2009; Screen et al. 2013) via the modulation of the stratospheric polar vortex (King et al. 2015; García-Serrano et al. 2015), or via the changes of transient eddies downstream of the North Atlantic storm track (García-Serrano et al. 2015; García-Serrano and Frankignoul 2016). The AMOC impacts on sea ice might therefore also contribute to the atmospheric response to the AMOC.
In the present study, we further investigate the AMOC impact on climate and the related mechanisms, using the IPSL-CM5A-LR climate model, which has been widely used in previous studies. Although it shows a rather large cold bias in the North Atlantic region (Dufresne et al. 2013), the air-sea interactions in the North Atlantic are realistically represented (Gastineau et al. 2013). A link between the AMOC and the winter atmosphere has been previously established in the coupled control simulation of this model (GF12; Gastineau et al.2013). Here, the causality links are more firmly established by performing atmospheric sensitivity studies. We use the atmospheric component of IPSLCM5A-LR in sensitivity experiments designed to investigate the AMOC impacts, and to separate and attribute the atmospheric response to the different surface forcings associated with the AMOC. In this following, we illustrate that the SSTs along the North Atlantic Current and in the subpolar North Atlantic region have a dominant influence on the atmospheric circulation changes, while the sea ice concentration (SIC) anomalies in the North Atlantic sector amplify the response to the SST, acting as a positive feedback. The stratosphere may contribute to this amplification.

\section{Winter atmospheric response to the $\mathrm{AMOC}$ in IPSL-CM5A-LR}

\section{a. Coupled model setup}

The IPSL-CM5A-LR climate model, where LR stands for low resolution, was developed at IPSL for the CMIP5 experiments (Dufresne et al. 2013). Its atmospheric component is LMDZ version 5A (LMDZ5A; Hourdin et al. 2013), where A indicates standard physical parameterizations. It has a low horizontal resolution of $2.5^{\circ}$ in latitude and $3.75^{\circ}$ in longitude, but it is a high-top model with 39 vertical levels up to $4 \mathrm{~Pa}$. The land surface model is ORCHIDEE (Krinner et al. 2005) with the same resolution as the atmosphere. The ocean model component is NEMO (Madec 2008) with the ORCA2 grid configurationhorizontal resolution of $2^{\circ}$ increasing to $0.5^{\circ}$ at the equator-coupled to the LIM version 2 (LIM2) sea ice model (Fichefet and Morales Maqueda 1999). We use the preindustrial control simulation, without any external forcing, and, to avoid the influence of model drift, only consider the last $500 \mathrm{yr}$ of the run, which were also analyzed in Gastineau et al. (2013). All coupled model outputs were linearly detrended before the analysis.

\section{b. Coupled model evaluation}

Many aspects of the IPSL-CM5A-LR coupled model are realistic. The weather regimes in the North Atlantic 
a)

Atlantic MSF : Mean and EOF1 (48.9\%)

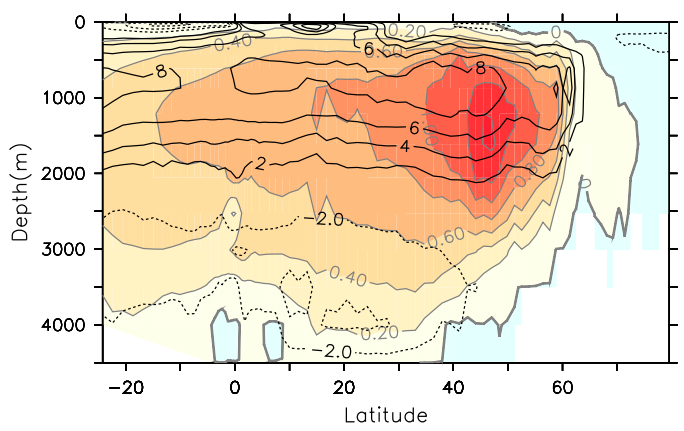

b)

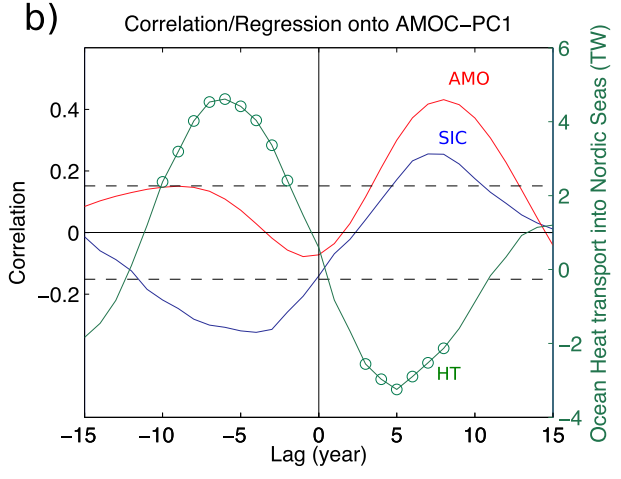

FIG. 1. (a) Mean Atlantic meridional streamfunction of IPSL-CM5A-LR (contours, Sv) and first EOF of the yearly Atlantic meridional streamfunction (colors, Sv). The variance percent explained by the first EOF is given at the top. (b) Correlation with AMOC-PC1 of the AMO index (red line) and the sea ice extent over the Nordic seas (blue line), and regression of the oceanic heat transport into the Nordic seas at $60^{\circ} \mathrm{N}$ onto AMOC-PC1 (green line). The lag is positive when AMOC-PC1 leads. The 10\% significance level of the correlation is indicated with dashed lines. The circles indicate when the regression is significant at the $10 \%$ level.

are fairly well simulated (Cattiaux et al. 2013), and the North Atlantic air-sea interactions are weaker but similar to those found in observations (Gastineau et al. 2013). The stratosphere exhibits an intraseasonal variability comparable to that of the observations, and sudden stratospheric warmings have a realistic impact on the troposphere (Vial et al. 2013). However, a large cold bias is simulated at about $40^{\circ}$ in both hemispheres in the atmosphere and the sea surface (see Dufresne et al. 2013, their Fig. 7), which is linked to the atmospheric jet stream being too equatorward (Hourdin et al. 2013), as found in many other climate models (Barnes and Polvani 2013).

The mean oceanic state has been described in Marti et al. (2010) in a version using slightly different resolutions and parameters, and in Escudier et al. (2013) for the present IPSL-CM5A-LR version. The Gulf Stream is too broad because of the coarse horizontal resolution and its position is too equatorward because of the bias in the zonal wind stress (see Fig. S1a in the supplemental material). IPSL-CM5A-LR simulates a mixed layer depth larger than $600 \mathrm{~m}$ in three distinct regions (see Fig. S1b), namely the Nordic seas, the Iceland basin and Irminger Sea, and at the exit of the Labrador Sea. Because of the large midlatitude cold bias that leads to an overextended sea ice cover in the Labrador Sea, the convection in the Labrador Sea is underestimated, while it is overestimated south of Iceland. Moreover, no deep water formation occurs on the shelf seas (see Mauritzen 1996), as in many other low-resolution models (Lohman et al. 2014). The mean AMOC (contours in Fig. 1a) reaches $9.7 \mathrm{~Sv}\left(1 \mathrm{~Sv} \equiv 10^{6} \mathrm{~m}^{3} \mathrm{~s}^{-1}\right)$ at $40^{\circ} \mathrm{N}$, which is below that inferred from RAPID-MOCHA [17.5 Sv at $26^{\circ} \mathrm{N}$; Smeed et al. (2014)]. The Nordic seas overflows are also underestimated, with only $2.2 \mathrm{~Sv}$ of dense water flowing southward (Escudier et al. 2013), compared to $6 \mathrm{~Sv}$ for the observations (Olsen et al. 2008).

\section{c. AMOC variability}

A large 20-yr periodicity has been identified in the AMOC and various ocean variables in the North Atlantic in this simulation of IPSL-CM5A (Escudier et al. 2013), suggesting a potential predictability of the AMOC, surface temperature, and precipitation in the North Atlantic at the decadal scale (Persechino et al. 2013). The AMOC variability in IPSL-CM5A-LR is illustrated in Fig. 1a (colors) by its first empirical orthogonal function (EOF). The first mode of variability is an overturning cell with a large vertical extension reaching down to $4000 \mathrm{~m}$. The 20 -yr periodicity is primarily related to the westward propagation of subsurface density anomalies in the subpolar basin, referred to as the subsurface basin mode in Ortega et al. (2015). Such variability has been identified in observations (Frankcombe et al. 2008) and in idealized ocean models (Colin de Verdière and Huck 1999; Jamet et al. 2016).

We define an AMO index as the yearly mean SST in the Atlantic Ocean $\left(0^{\circ}-60^{\circ} \mathrm{N}, 80^{\circ} \mathrm{W}-0^{\circ}\right)$, low-pass filtered with a third-order Butterworth filter, using $10 \mathrm{yr}$ as a cutoff period. The lagged correlation between the $\mathrm{AMO}$ and the first principal component (PC) of the AMOC (AMOC-PC1) is significant when the AMOC leads by $5-12 \mathrm{yr}$, with a maximum of 0.42 at lag 8 (Fig. 1b, red line), so that an increase in the AMOC is followed by a warm AMO phase. The statistical significance was tested with moving-block bootstraps using 100 resamplings of a $30-y r$ block, to account for the reduction in degrees of freedom due to the low-pass filter. 

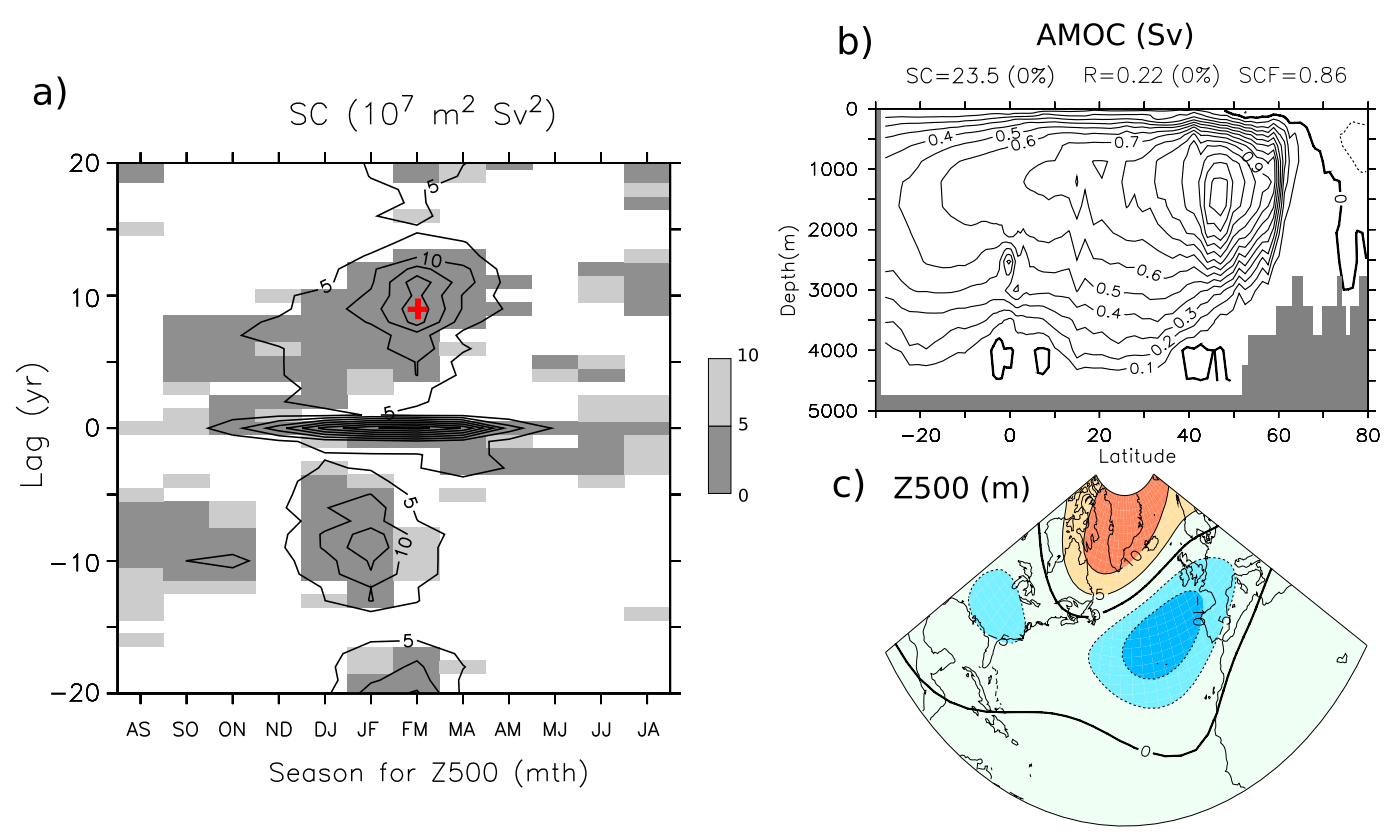

FIG. 2. Results of the MCA between the yearly Atlantic meridional streamfunction and Z500 in IPSL-CM5ALR. (a) Squared covariance (SC, $10^{7} \mathrm{~m}^{2} \mathrm{~Sv}^{2}$ ) of the first mode (contours) and the SC level of significance (shading), using a 2-month average for Z500. The lag is positive when the AMOC leads. The maximum SC results for lags $>1 \mathrm{yr}$ is indicated with a red cross. (b) Atlantic meridional streamfunction homogeneous covariance map (Sv) for the first MCA mode when the AMOC leads Z500 in FM by $9 \mathrm{yr}$. The associated SC $\left(10^{7} \mathrm{~m}^{2} \mathrm{~Sv}^{2}\right)$, the correlation $R$, their respective levels of significance, and the squared covariance fraction (SCF) are indicated at the top. (c) As in (b), but for the Z500 heterogeneous covariance map (m).

In contrast to other models (Allison et al. 2015; Zhang 2015), the AMOC does not lead to a warming of the Nordic seas in IPSL-CM5A-LR, as the sea ice extent in the Nordic seas increases almost in phase with the warming of the subpolar SST (Fig. 1b, blue line). As shown in Fig. 1b, the AMOC is followed 8 yr later by a surface warming of the subpolar basin, consistent with the increased northward heat transport from the subtropical Atlantic to the subpolar basin. Ortega et al. (2015) argued that this warming is associated with negative density and anticyclonic ocean circulation anomalies in the eastern subpolar basin between 300 and $1000 \mathrm{~m}$, which follow the AMOC by $5 \mathrm{yr}$. This leads to a reduction of the oceanic northward heat transport into the Nordic seas, which also occurs about $5 \mathrm{yr}$ after an intensification of the AMOC (Fig. 1b, green line) mainly because of the anomalous currents across the Denmark Strait: the southward East Greenland Current is reduced, while less warm and salty water from the North Atlantic is advected into the Nordic seas (Fig. S2 in the supplemental material). Therefore, in IPSL-CM5A-LR, a larger AMOC is followed by more sea ice over the Nordic seas.

\section{d. AMOC impact}

The AMOC influence onto the atmosphere is investigated as a function of the season using a lagged maximum covariance analysis (MCA) between bimonthly 500-hPa geopotential height (Z500) anomalies in the North Atlantic sector and the yearly Atlantic meridional overturning streamfunction between $30^{\circ} \mathrm{S}$ and $80^{\circ} \mathrm{N}$, as presented in more details in GF12. The MCA decomposes the covariance matrix of the two fields using singular value decomposition (Bretherton et al. 1992), leading to different modes of covariability characterized by a spatial pattern for each field (the covariance map) and their time evolution (the MCA time series). When the AMOC leads by a time lag longer than the persistence of atmospheric circulation anomalies, the first MCA mode, if statistically significant, may show the atmospheric impact of the AMOC. The MCA modes are tested with their squared covariance (SC, i.e., the squared singular value) and the correlation $R$ between the two MCA time series. To estimate statistical significance while accounting for temporal autocorrelation, we use 100 random permutations of a block of three consecutive years for Z500. The quoted significance levels indicate the numbers of randomized SCs and correlation $R$ that exceed the value being tested, as in GF12. Figure 2 shows the SC of the first MCA mode and its statistical significance. When the ocean leads (positive lag), the SC of the first MCA mode is significant from lag 4 to lag 13 (in yr), and largest at lag 9 during 
a) SST $(K)$
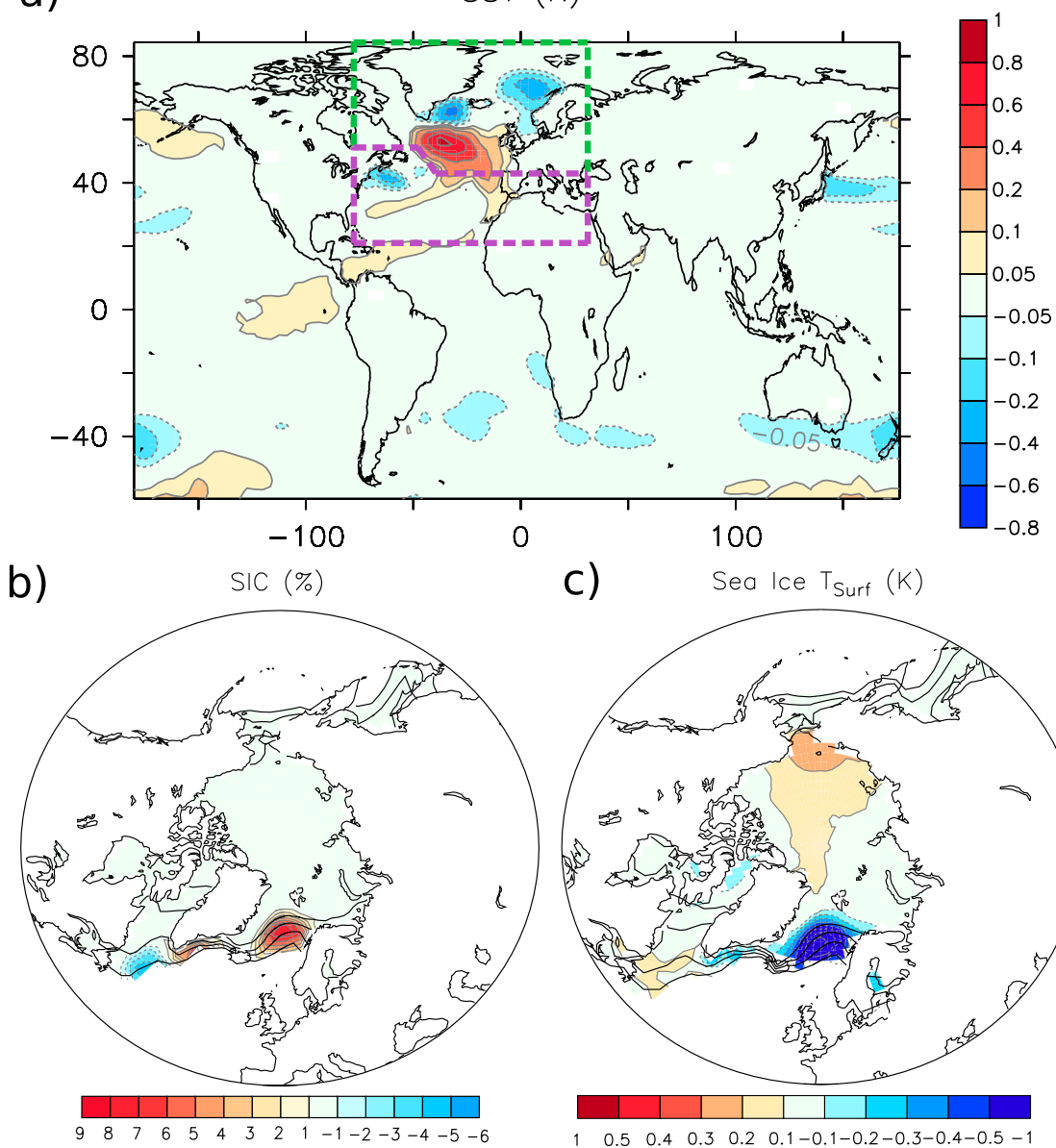

C) Sea Ice $T_{\text {Surf }}(K)$

IG. 3. Regression onto AMOC-PC1 with the AMOC leading by $9 \mathrm{yr}$ in winter (ONDJFM) for (a) SST (K), (b) SIC (\%), and (c) the sea ice surface temperature (K). In (b),(c), the mean climatological SIC is given by thin black contours (contour interval is $20 \%$ from $20 \%$ to $80 \%$ ). The purple and green boxes in (a) indicate the regions used to perform the ensemble simulations.

February-March (FM). The AMOC and Z500 covariance maps corresponding to the maximum $\mathrm{SC}$ are shown in Figs. $2 \mathrm{~b}$ and $2 \mathrm{c}$, but other lags provide similar patterns. Figure 2 shows an AMOC pattern similar to the first AMOC EOF (cf. Figs. 2b and 1a) leading to negative NAO-like atmospheric changes.

As the AMOC MCA time series has a correlation of 0.98 with AMOC-PC1, hereafter we use linear regression onto AMOC-PC1 to investigate the signature of the AMOC in the surface and atmospheric fields. The statistical significance is again tested using 100 random permutations of 3-yr blocks. We only show the regressions when the AMOC leads by $9 \mathrm{yr}$, as it is associated with the largest atmospheric response. The winter changes are identical to those described in GF12, but they are derived by a simpler methodology.

An intensification of the AMOC precedes a surface warming in the subpolar domain, shown here for the whole cold season [October-March (ONDJFM); see Fig. 3a]. The subpolar warming is accompanied by a weak surface warming of the Caribbean Sea and the western North Atlantic subtropical gyre, while there is a cooling in the Nordic seas, as well as near the Gulf Stream. The SST anomalies are small in the other basins. Such a pattern shares numerous similarities with the AMO of that model, especially for the subpolar warming, even if some differences can be noticed near the Gulf Stream or in the tropical regions, as found by Marini and Frankignoul (2014).

In parallel, the sea ice extent decreases over the Labrador Sea, but increases in the Nordic seas (Fig. 3b). The sea ice surface temperatures are consistent with the SST anomalies near the sea ice edge, and show a warming of about $0.1 \mathrm{~K}$ over the central Arctic (Fig. 3c).

The anomalous SST and SIC evolve during the cold season. The SST anomalies are doubled in size in late winter (Fig. 4a, red curve) while the sea ice extent 


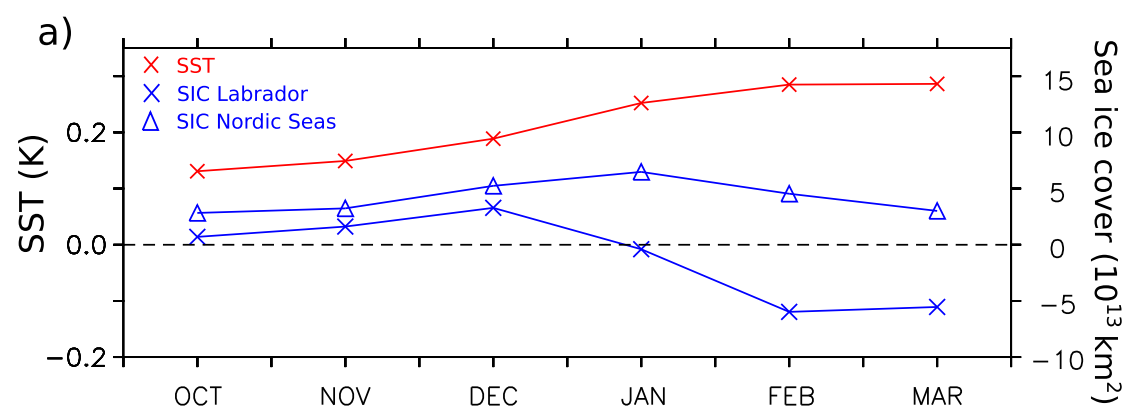

b)

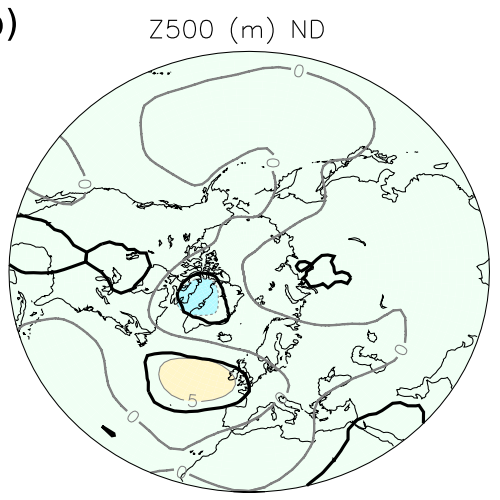

c)

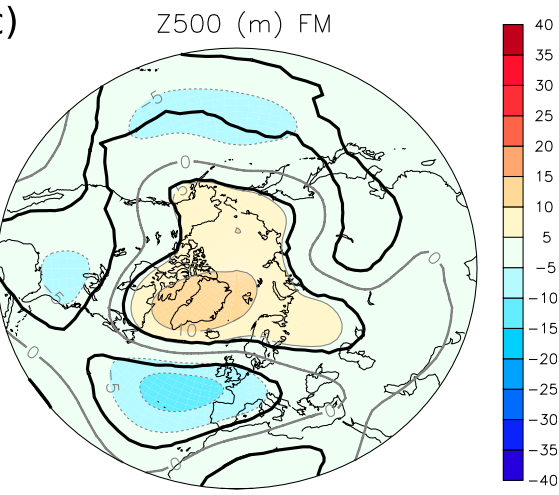

T (K) Polar cap

d)

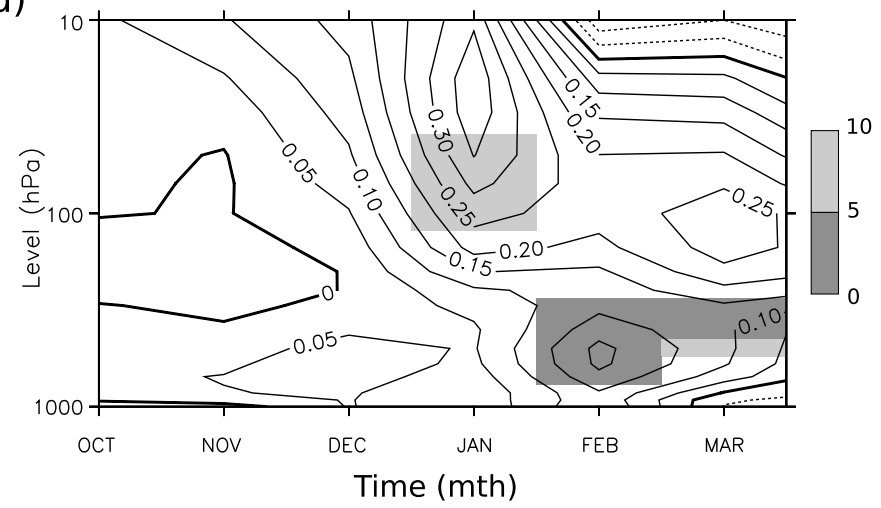

FIG. 4. In IPSL-CM5A-LR, (a) amplitude of the monthly anomalies for SST (K, left $y$ axis) and sea ice extent $\left(10^{13} \mathrm{~km}^{2}\right.$, right $y$ axis) during the cold season (ONDJFM) given by the regression onto AMOC-PC1 with the AMOC leading by $9 \mathrm{yr}$ for the SST averaged over the Atlantic Ocean $\left(40^{\circ}-60^{\circ} \mathrm{N}, 50^{\circ} \mathrm{W}-0^{\circ}\right.$; red line), for the SIC in the Labrador Sea $\left(50^{\circ}-75^{\circ} \mathrm{N}, 70^{\circ}-\right.$ $40^{\circ} \mathrm{W}$; blue line with crosses), and for the Nordic seas $\left(50^{\circ}-75^{\circ} \mathrm{N}, 40^{\circ} \mathrm{W}-0^{\circ}\right.$; blue line with triangles). (b) Regression onto AMOC-PC1 with the AMOC leading by $9 \mathrm{yr}$ for Z500 in early winter (November-December) (m). (c) As in (b), but for late winter (FM). In (b), (c) the black contours indicate statistical significance at the $10 \%$ level. (d) Regression onto AMOC-PC1 of the monthly zonal-mean temperature anomalies $(\mathrm{K})$ over the polar cap $\left(60^{\circ}-90^{\circ} \mathrm{N}\right)$. The significance is shown by gray shading.

increases over the Labrador Sea in early winter, but then decreases after December (Fig. 4a, blue curve). The sea ice extent increase over the Nordic seas is more stable. The atmospheric response also evolves, as illustrated by the lagged Z500 regression onto the AMOC-PC1. Two contrasting responses occur. In late fall-early winter (November-December), there is a weak anticyclone over the northeastern Atlantic and a small cyclonic perturbation over the Labrador Sea (Fig. 4b). No significant response is found in January, but, as illustrated previously, in late winter (FM) there is a strong dipolar response in the North Atlantic sector, with weaker anomalies over the Pacific Ocean and Eurasia, which projects onto a negative phase of the Arctic Oscillation (Fig. 4c). To establish if the stratosphere is playing a role, the monthly mean temperature anomalies, 
TABLE 1. Description of the atmosphere-only simulation ensembles.

\begin{tabular}{|c|c|c|c|}
\hline Expt & Ensemble size & SST & Sea ice \\
\hline CTR & 75 & Climatology from IPSL-CM5A-LR & Climatology from IPSL-CM5A-LR \\
\hline $\mathrm{Atl}_{\mathrm{ALL}}$ & 75 & $\begin{array}{l}\text { Anomalies from AMOC-PC1, regression at lag } \\
9 \mathrm{yr} \text {, north of } 20^{\circ} \mathrm{N} \text { in the Atlantic Ocean }\end{array}$ & $\begin{array}{l}\text { Anomalies from AMOC-PC1, regression at } \\
\text { lag } 9 \mathrm{yr} \text {, in the Atlantic and Arctic Oceans }\end{array}$ \\
\hline Atl $_{\text {SST }}$ & 75 & As in $\mathrm{Atl}_{\mathrm{ALL}}$ & Climatology from IPSL-CM5A-LR \\
\hline Atl $_{\text {SST-N }}$ & 75 & $\begin{array}{l}\text { As in } \mathrm{Atl}_{\mathrm{ALL}} \text {, but using only anomalies in the } \\
\text { Atlantic north of } 45^{\circ} \mathrm{N}\end{array}$ & Climatology from IPSL-CM5A-LR \\
\hline $\mathrm{Atl}_{\mathrm{SST}-\mathrm{S}}$ & 75 & $\begin{array}{l}\text { As in } \text { Atl }_{\mathrm{ALL}} \text {, but using only anomalies in the } \\
\text { Atlantic south of } 45^{\circ} \mathrm{N}\end{array}$ & Climatology from IPSL-CM5A-LR \\
\hline
\end{tabular}

averaged over the polar cap between $60^{\circ}$ and $90^{\circ} \mathrm{N}$, are given in Fig. 4d. In late fall-early winter, there is no significant signal in IPSL-CM5A-LR, but in January, there is an anomalous warming of the lower stratosphere, followed in FM by tropospheric warming. Omrani et al. (2014) argued that the Atlantic SST anomalies are able to cause a stratospheric warming during early and midwinter in the observations, which then propagates downward, resulting in an amplification of the tropospheric negative NAO in late winter. The warming of the stratosphere in January indicates a possible role for the stratosphere in the formation of the late winter NAO, as found in Omrani et al. (2014).

Hereafter, we mostly focus on the late winter signal and perform a sensitivity study to bring out the different mechanisms involved in the atmospheric response.

\section{Atmospheric response to the AMOC SST and sea ice fingerprint in the North Atlantic}

\section{a. Atmosphere-only sensitivity experiments}

To investigate the processes leading to the atmospheric changes linked to the AMOC, ensembles of atmosphereonly simulations were performed using the IPSL-CM5ALR atmospheric (i.e., LMDZ5A) and land surface (i.e., ORCHIDEE) model components. The atmospheric model offers an oversimplified representation of the heat flux exchange over sea ice tiles, assuming constant thermal conductivity and sea ice thickness, with the temperature of the sea ice base being fixed at the seawater freezing point. This simplification generates quite unrealistic surface temperatures over sea ice in the atmosphere-only simulations. To avoid an important difference between the coupled and atmospheric models, the surface temperature over sea ice tiles was prescribed in the atmosphere-only simulations, based on IPSL-CM5A-LR.

An ensemble of 75 members (CTR) was first constructed by prescribing an SST and SIC climatology taken from IPSL-CM5A-LR. Each simulation starts on 1 October from an atmospheric state taken randomly from an atmospheric simulation in perpetual 1 October conditions, with the same land surface initial state as in
IPSL-CM5A-LR. The simulations end on 30 March, at the end of the cold season. To prescribe the SST and sea ice anomalies, which are localized in the North Atlantic and Arctic, daily SST, SIC, and sea ice surface temperature were regressed onto AMOC-PC1 in the coupled simulation, when AMOC-PC1 leads by $9 \mathrm{yr}$. The daily values from October to February at year $n$ are regressed using the yearly AMOC-PC1 index at year $n-9$. They were smoothed by 10-day running averaging and added to the climatology of the coupled model to force the ensemble simulations.

To investigate the role of the surface anomalies linked to the AMOC variability, a first experiment, $\mathrm{Atl}_{\mathrm{ALL}}$, is performed, using the SST, SIC, and sea ice surface temperature anomalies over the North Atlantic basin (domain defined by the addition of the green and purple boxes in Fig. 3a from $20^{\circ}$ to $90^{\circ} \mathrm{N}$ ). The experiment Atl $_{\text {SST }}$ is identical, but only uses the North Atlantic SST anomalies, keeping sea ice and surface sea ice temperature at their climatological values.

The experiment Atl SST-N $_{\text {only }}$ uses the warm SST anomalies over the subpolar North Atlantic and the Nordic seas, located north of $45^{\circ} \mathrm{N}$ in the western Atlantic (Fig. 3a, green box) while Atl SST-S $_{\text {only uses the }}$ SST anomalies in the subtropical North Atlantic and the Gulf Stream region (Fig. 3a, purple box). For these two simulations we smoothed the anomalies at the edge of the domain along $45^{\circ} \mathrm{N}$, using a moving average over three grid points in latitude.

All experiments have 75 members. Table 1 provides a summary of the experiments and their boundary conditions. Hereafter, the ensemble means are presented and discussed, while the variability among members is used to measure the uncertainty of the atmospheric response.

\section{b. Differences between coupled and atmosphere-only simulations}

The mean state of the CTR simulation is compared to that of the IPSL-CM5A-LR coupled model in order to validate our experimental protocol, as differences in the mean climate can lead to different sensitivities to boundary forcing (Peng et al. 1997). The lower 

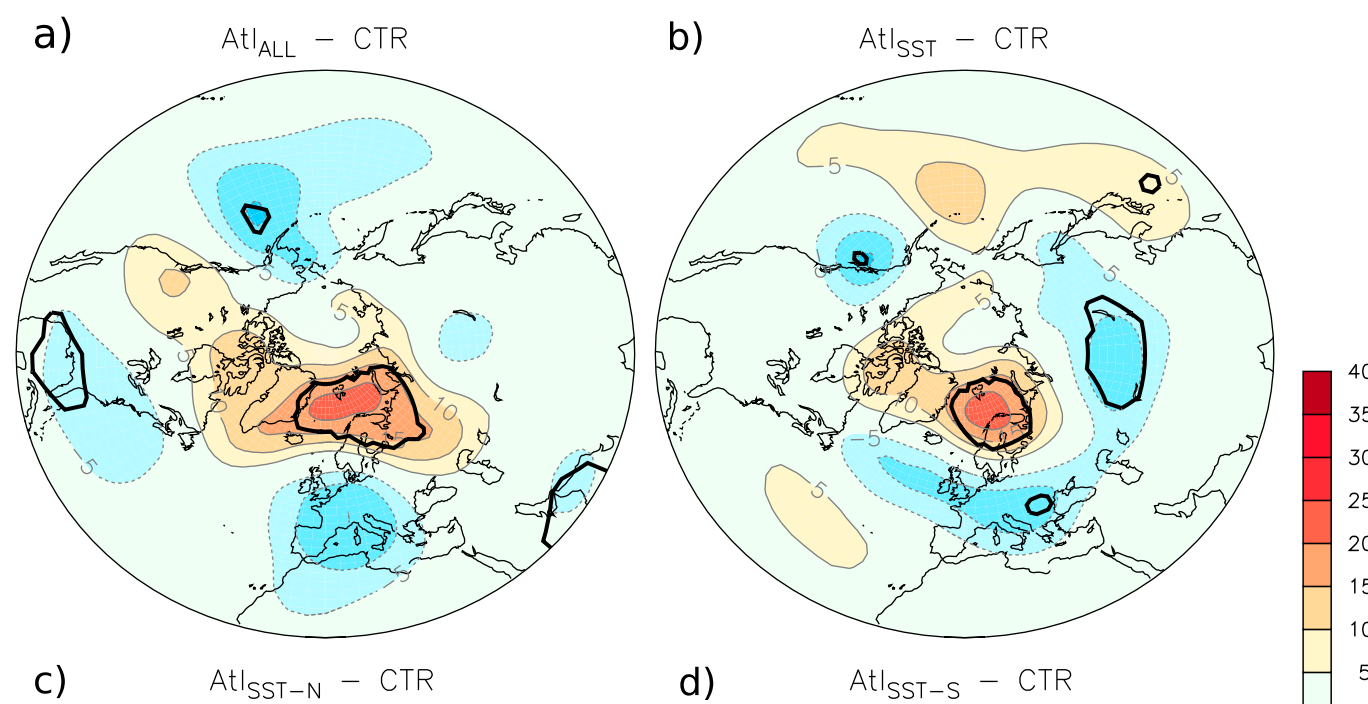

c)

AtISST-N - CTR

d)
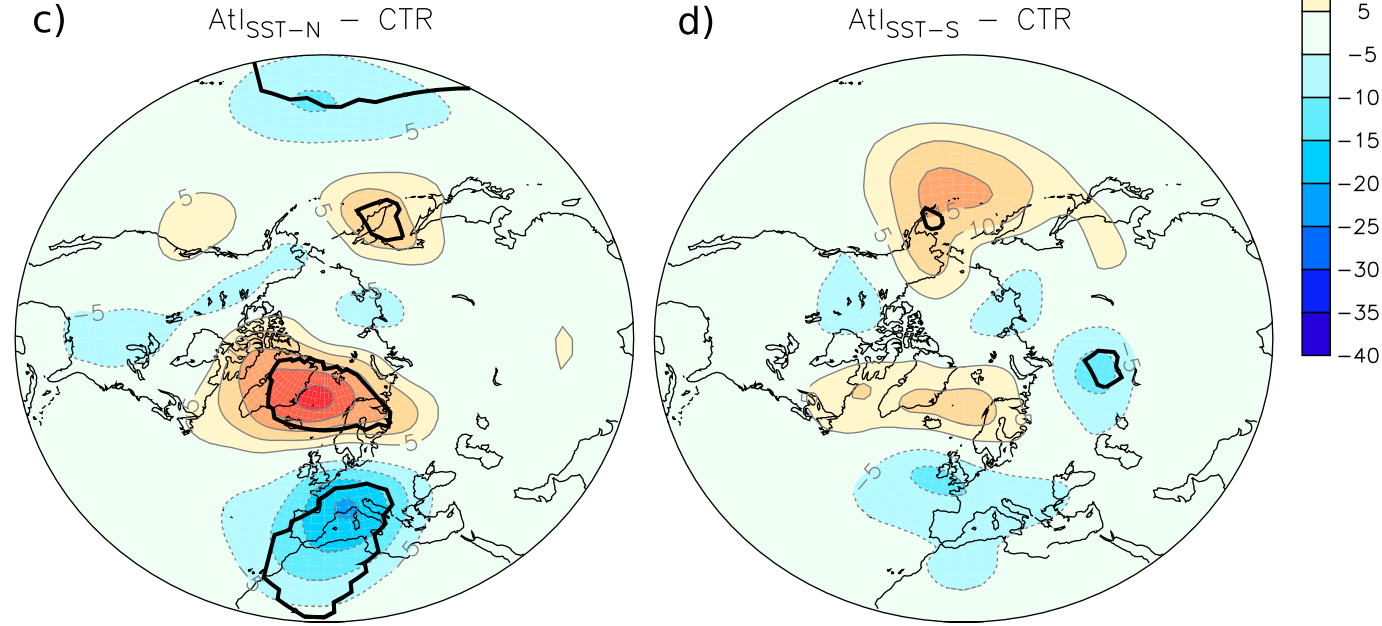

FIG. 5. Response of Z500 (m) in the sensitivity experiments during late winter (FM) given by the differences in the simulations: (a) Atl ALL $_{- \text {CTR, (b) Atl }}$ SST - CTR, (c) Atl SST-N $_{\text {- CTR, and (d) Atl }}$ SST-S - CTR. The black contours indicate significance at the $10 \%$ level.

troposphere is colder in CTR over both sea ice and land grid points (Fig. S3a in supplemental material). This can be due to the differing sea ice treatment in the two models or to differences in the land surface initial conditions. As a result, the land surface temperatures in northern North America, the Arctic, and eastern Asia are from 0.5 to $1.5 \mathrm{~K}$ colder in the atmosphere-only simulation, with the largest bias over Canada and Greenland. However, this bias remains confined to the surface (Fig. S3b). Another important bias is in the cold stratosphere during October (Fig. S3c), as the initial states are generated using a perpetual simulation in 1 October conditions, when the stratosphere experiences radiative cooling. However, this bias vanishes in a few months and is not found in late winter when the atmospheric response to the AMOC is largest.

In summary, the mean state of the atmospheric GCM ensemble simulations and that of IPSL-CM5A-LR have considerable similarities. The simulations with the AMOC SST and sea ice anomalies can be used to understand the atmospheric impacts of the AMOC in the IPSL-CM5A-LR coupled model.

\section{c. Atmospheric response}

The Z500 anomalies in the sensitivity experiments are plotted for late winter (FM) in Fig. 5. Here and in the following, the statistical significance is established using a two-sample Student's $t$ test to compare the ensemble mean of each experiment to that of the CTR simulation, each member being considered as independent.

The simulation $\operatorname{Atl}_{\mathrm{ALL}}$ (Fig. 5a) using the whole boundary forcing in the North Atlantic produces an NAO-like pattern close to that in IPSL-CM5A-LR (see Fig. 4c). It captures relatively well the anomalous dipolar structure over the North Atlantic, with a high over the Nordic seas and a low over the Atlantic midlatitudes 
a)

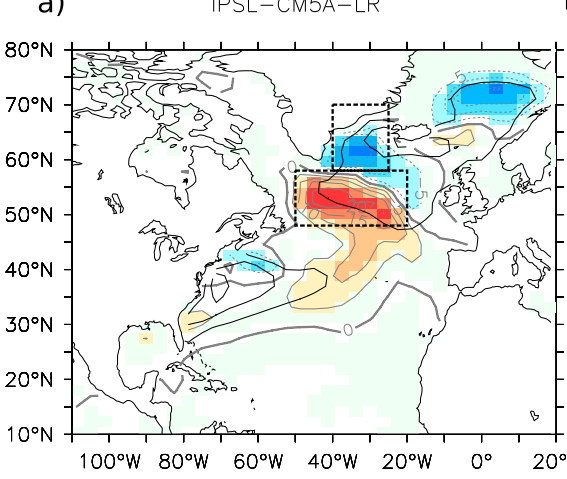

b)

AtI $_{\text {ALL }}-$ CTR

C)

AtISST $_{\text {S CTR }}$

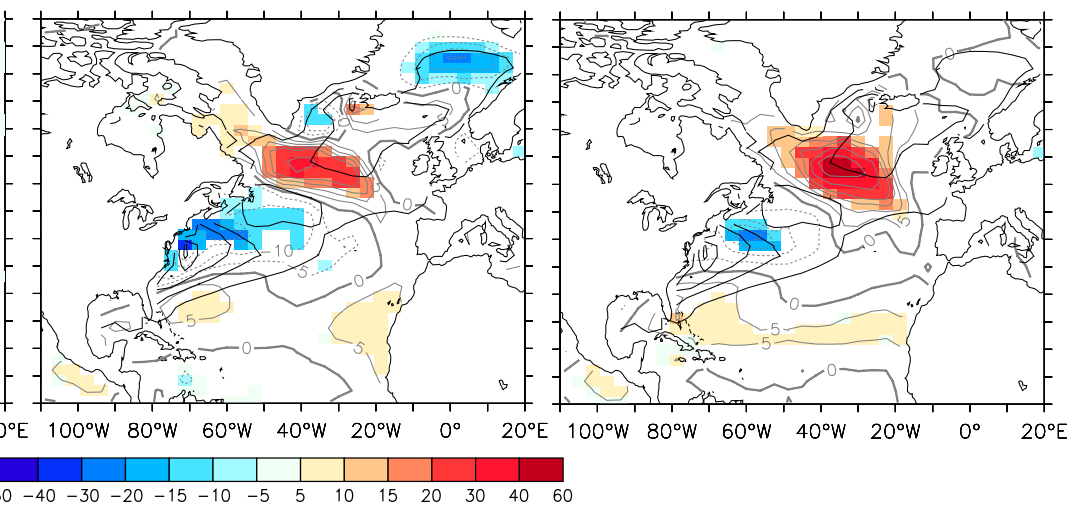

FIG. 6. Total surface heat flux anomalies, positive upward ( $\mathrm{W} \mathrm{m}^{-2}$; same gray contour interval as in the color bar), averaged during FM, for (a) the regression onto AMOC-PC1 when AMOC leads by $9 \mathrm{yr}$ in IPSL-CM5A-LR. (b) The difference between the simulations $\mathrm{Atl}_{\mathrm{ALL}}-\mathrm{CTR}$ and (c) the simulations Atl $\mathrm{SST}_{\mathrm{C}}$ - CTR. The black contours indicate the climatology of (a) IPSL-CM5A-LR and in (b),(c) of CTR (contour interval is $100 \mathrm{~W} \mathrm{~m}^{-2}$, from 100 to $500 \mathrm{~W} \mathrm{~m}^{-2}$ ). The colors are masked if the anomalies are not significant at the $10 \%$ level. The dashed boxes in (a) indicate the regions chosen to evaluate the atmospheric diabatic heating in Fig. 7.

from the southern United States to western Europe. However, the anomalies are shifted eastward, and they are not significant over the eastern North Atlantic. Some negative anomalies are also found over the northern Pacific Ocean, which indicates that $\mathrm{Atl}_{\mathrm{ALL}}$ reproduces the Arctic Oscillation-like extension of the atmospheric response seen in the coupled model. We hypothesize that the differences between the coupled model and $\mathrm{Atl}_{\mathrm{ALL}}-\mathrm{CTR}$ are due to the large internal atmospheric variability that reduces the signal-to-noise ratio, and to the differences in the mean state, especially over the Arctic Ocean and northern Canada, as discussed in section $3 b$.

The Atl SST $_{\text {simulations, which only use SST anomalies }}$ as boundary forcing, show a similar high over the Nordic seas (Fig. 5b) although it is smaller than in $\mathrm{Atl}_{\mathrm{ALL}}$. Furthermore, the Z500 anomalies are different over the subtropical Atlantic. The experiment Atl SST-N with partial SST anomaly forcing shows a large significant geopotential height dipole over the North Atlantic, even if the dipole is again shifted northeastward compared to IPSL-CM5A-LR (Fig. 5c). Conversely, the changes in $\mathrm{Atl}_{\text {SST-S }}$ are smaller and not significant, albeit with a

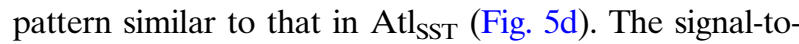
noise ratio is small so that the differences among Atl SST $_{\text {, }}$ Atl $_{\text {SST-N }}$, and Atl SST-S $_{\text {S }}$ are not $10 \%$ significant (not shown). Nonetheless, the SST anomalies in the northern part of the North Atlantic domain seem to have the largest impact, although the atmosphere can also be influenced by the subtropical SST anomalies, even if they are 3 times weaker (cf. SST anomalies in the northern and southern rectangles in Fig. 3a). As the sum of the response in Atl SST-N $_{\text {and }}$ Atl SST-S $_{\text {is }}$ much larger than the response simulated in $\mathrm{Atl}_{\mathrm{SST}}$, the atmospheric response to midlatitude SST anomalies behaves nonlinearly, as found previously by Peng et al. (2003) and Drévillon et al. (2001), among others. We now investigate how such surface anomalies have an impact on the troposphere.

\section{d. Heating anomalies}

The surface heat flux changes induced by the SST and SIC anomalies are diagnosed using the simulations $\mathrm{Atl}_{\mathrm{SST}}$ and $\mathrm{Atl} \mathrm{ALL}_{\mathrm{ALL}}$. The surface heat flux anomalies are given in Fig. 6 for FM, and are simultaneous to the atmospheric response described above. They show that in both coupled and forced simulations, the negative heat flux feedback (Frankignoul et al. 1998; Park et al. 2005) explains the occurrence of an upward (downward) heat flux over warm (cold) SST anomalies. The heat flux pattern compares best with the coupled model in Atl $\mathrm{ALL}_{\mathrm{AL}}$, in particular near the sea ice edge, but the heat flux is nearly doubled in size in the atmosphere-only simulations as a result of the absence of coupling (Barsugli and Battisti 1998). This may explain the overestimation of the atmospheric circulation changes shown previously. The comparison between $\mathrm{Atl}_{\mathrm{ALL}}$ (Fig. 6b) and $\mathrm{Atl}_{\mathrm{SST}}$ (Fig. 6c) shows that the SIC anomalies have a comparable impact in term of amplitude on the surface heat exchanges to that of the SST anomalies, but are located over the sea ice edge in the Labrador and Nordic seas.

The influence of the surface heat flux onto the lower troposphere is illustrated by the anomalous diabatic heating in FM at two locations indicated by the black dashed lines in Fig. 6a. These locations are restricted to the surroundings of the largest surface anomalies in order to estimate the local diabatic heating response, and are referred to as Box-N and Box-S. Above the warm

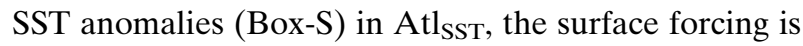



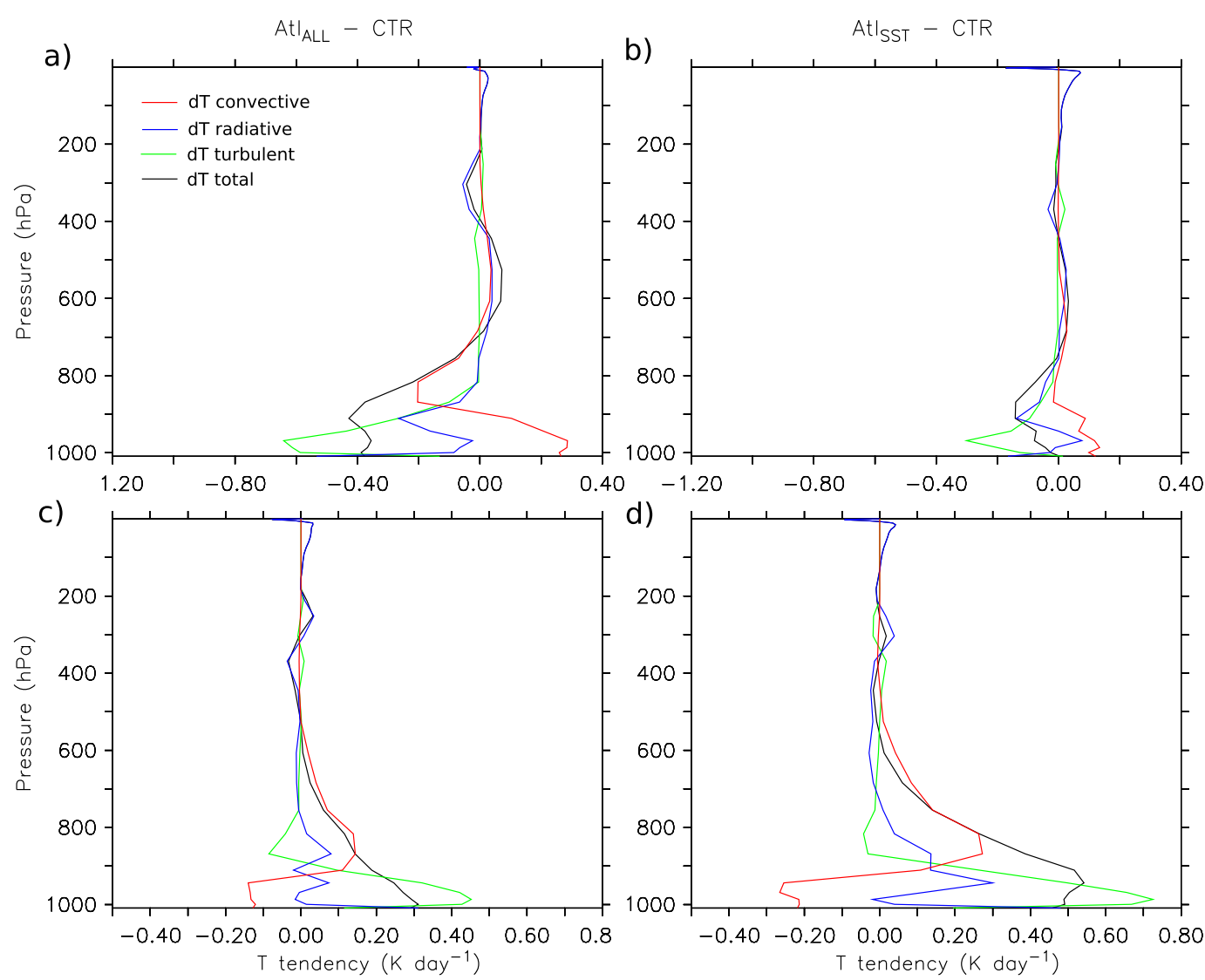

FIG. 7. Anomalous diabatic heating $\left(\mathrm{K} \mathrm{day}^{-1}\right)$-convective (red), radiative (blue), turbulent (green), and total (black) — induced by the boundary conditions in FM over the Irminger Sea (Box-N, the northern box in Fig, 6a) for (a) Atl $\mathrm{ALL}_{\mathrm{C}}$ - CTR and (b) Atl $\mathrm{SST}_{\mathrm{C}}$ - CTR. (c),(d), As in (a),(b), but for the subpolar North Atlantic SST anomalies (Box-S, the southern box in Fig. 6a).

propagated upward by the boundary layer scheme through the larger turbulent sensible heat flux in the first atmospheric levels between 1000 and $900 \mathrm{hPa}$, and conversely for a cold SST anomaly (Figs. 7c and 7d, green lines). Between 900 and $750 \mathrm{hPa}$, the diabatic heating remains large and positive over warm SST anomalies, as the water vapor from the surface evaporation condensates (Fig. 7, red line). The clouds at the top of the planetary boundary layer are less frequent over warm SSTs, which acts to reflect less shortwave radiation and warms the lower troposphere (Fig. 7, blue line), as discussed in L'Hévéder et al. (2015). The diabatic warming is weaker above $600 \mathrm{hPa}$. Over the sea ice anomalies located in the Irminger Sea (Box-N), the diabatic heating has similar characteristics, but is of opposite sign and results from the presence of SIC anomalies (Figs. 7a and 7b).

Previous studies have linked the diabatic heating of the lower troposphere to the storm track over the midlatitude (Hoskins and Valdes 1990). The changes of the storm tracks are, therefore, analyzed in the following.

\section{e. Storm track and eddy feedback}

The baroclinicity of the atmosphere is evaluated using the maximum Eady growth rate (Hoskins and Valdes 1990), defined at $850 \mathrm{hPa}$ as $0.31 f|\partial \mathbf{U} / \partial z| N^{-1}$ with $f$ the Coriolis parameter, $\partial \mathbf{U} / \partial z$ the horizontal wind shear, and $N$ the Brunt-Väisälä frequency. The storm track activity is measured by the bandpass- (2-6 days) filtered geopotential height variance at $500 \mathrm{hPa}$ (Blackmon et al. 1977). The IPSL-CM5A-LR coupled model shows a southward shift of the baroclinicity relative to its climatological position in the region of maximum eddy growth over the Gulf Stream/North Atlantic Current (Fig. 8a). This acts to decrease and shift southward the eddy activity downstream over the storm track, especially over the northeastern part of the Atlantic domain (Fig. 8d). Previous studies have argued that the largescale atmospheric response following the AMOC or the AMO is mainly a consequence of such a shift in the baroclinicity in the main eddy-developing region (GF12; Gastineau and Frankignoul 2015; Peings and 
a)

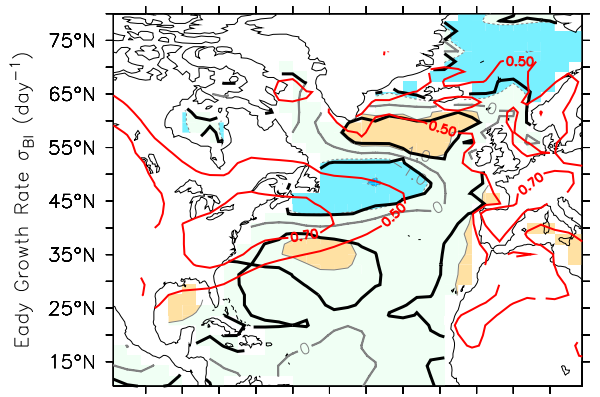

b)

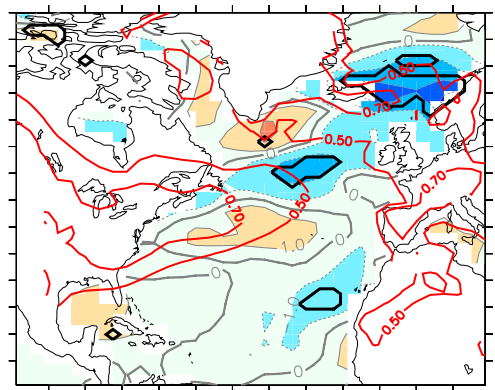

c)

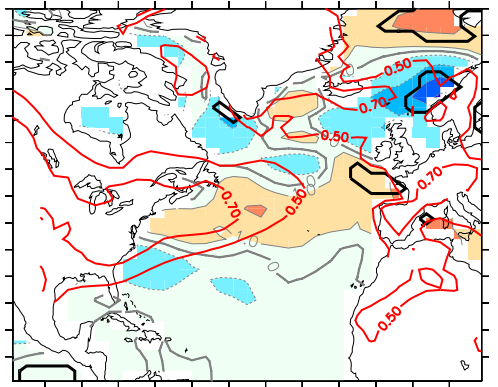

e)
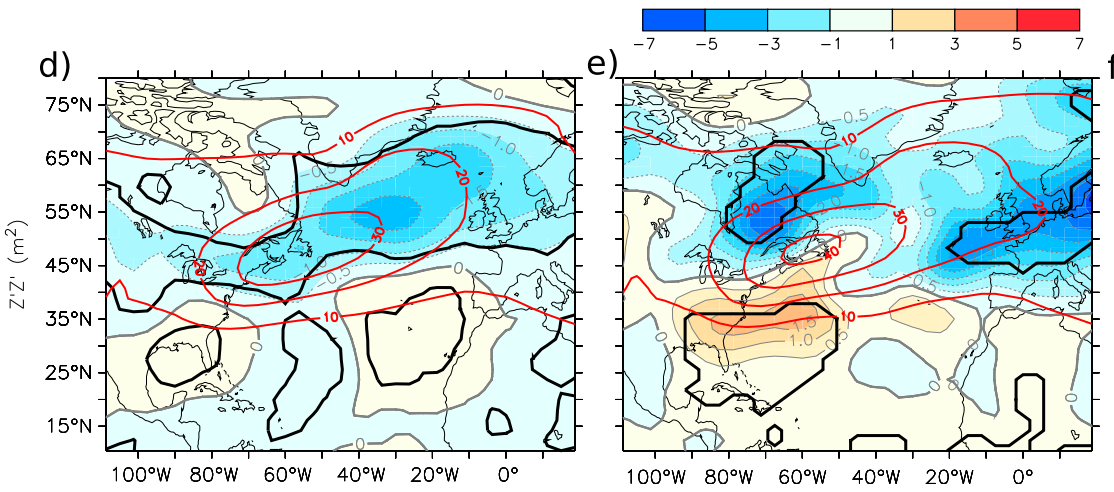

f)

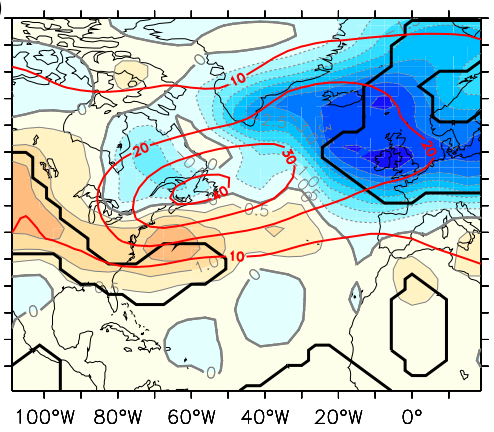

$100^{\circ} \mathrm{W} \quad 80^{\circ} \mathrm{W} \quad 60^{\circ} \mathrm{W} \quad 40^{\circ} \mathrm{W} \quad 20^{\circ} \mathrm{W} \quad 0^{\circ}$

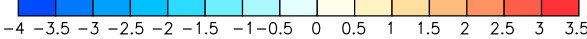

FIG. 8. (top) Maximum Eady growth rate $\left(10^{-2}\right.$ day $\left.^{-1}\right)$ and (bottom) 500-hPa geopotential height variance $\left(10^{2} \mathrm{~m}^{2}\right)$, in FM, regressed for (a),(d) IPSL-CM5A-LR onto AMOC-PC1, when the AMOC leads by $9 \mathrm{yr}$, or given by (b),(e) Atl ALL $_{-}$CTR and (c),(f) Atl SST $_{-}$ CTR. The climatology is given by red contours [day ${ }^{-1}$ in (a)-(c) and $10^{2} \mathrm{~m}^{2}$ in (d)-(f)] for IPSL-CM5A-LR in (a),(d) and for CTR in (b),(c),(e),(f). The black contours indicate significance at the $10 \%$ level.

Magnusdottir 2014). The simulations in $\mathrm{Atl}_{\mathrm{ALL}}$ show a similar but less significant southward shift of the baroclinicity (Fig. 8b), but the storm track activity displays a more significant southward shift over the western Atlantic, as shown by the larger anomalies simulated in $\mathrm{Atl}_{\mathrm{ALL}}$ south of Cape Hatteras (Fig. 8e). The downstream weakening in the North Atlantic is also stronger and occurs farther downstream than in the coupled run. In Atl $\mathrm{SST}_{\mathrm{ST}}$, the baroclinicity changes are weaker (Fig. 8c), but the pattern is broadly consistent with that in $\mathrm{Atl}_{\mathrm{ALL}}$, except off the European coasts and over the northern part of the Nordic seas. The storm track still shows a large southward shift over the southern United States and a large weakening over northern Europe (Fig. 8f). We conclude that the changes in baroclinicity are acting similarly in the coupled model and in $\mathrm{Atl}_{\mathrm{ALL}}$ or Atl $\mathrm{SST}$. This is consistent with the large influence of the meridional SST gradient changes in the main eddy growth region located over the Gulf Stream/North Atlantic Current region, as found by GF12, Gastineau and Frankignoul (2015), and Peings and Magnusdottir (2014).

To better understand the role of eddies, we calculated the eddy meridional heat flux $v^{\prime} T^{\prime}$ at $850 \mathrm{hPa}$ and the eddy meridional zonal momentum transport at
250-hPa $u^{\prime} v^{\prime}$, using 2-6-day bandpass-filtered variables (Blackmon et al. 1977). In IPSL-CM5A-LR, the meridional SST gradient decreases off Newfoundland (see Fig. 3a), and the northward meridional heat transport at $850 \mathrm{hPa}$ diminishes over that region and downstream (Fig. 9d). The northward momentum transport at $250 \mathrm{hPa}$ also decreases over the Gulf Stream, the western subtropical North Atlantic, and most of Europe (Fig. 9g). The vertical (horizontal) divergence of the meridional heat (momentum) flux yields the zonal wind tendencies induced by transient eddies in the EliassenPalm (EP) theory (Trenberth 1986). The two eddy fluxes act to weaken the eddy-driven jet, which in turn further amplifies the atmospheric response, illustrating the classical positive eddy feedback (Peng et al. 1997). As a result of the eddy changes in IPSL-CM5A-LR, the zonal eddydriven jet is shifted southward in the lower troposphere between 1000 and $400 \mathrm{hPa}$, while between 400 and $150 \mathrm{hPa}$, the subtropical jet is more intense (Fig. 9a).

Similar effects are seen in $\mathrm{Atl}_{\mathrm{ALL}}$. The prescribed SST anomalies cause a decrease in the northward meridional heat transport at $850 \mathrm{hPa}$ in the region of maximum eddy growth off the coast of Newfoundland and over the British Isles (see Fig. 9e). On the other hand, the changes in the 


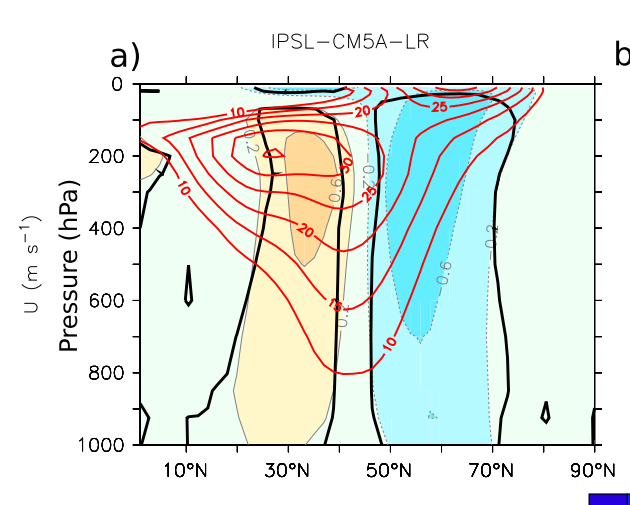

b)

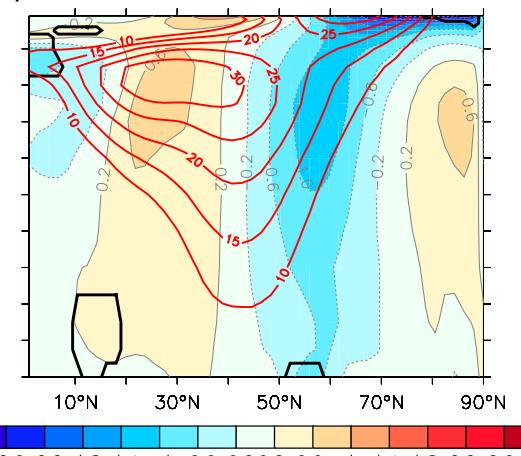

c)

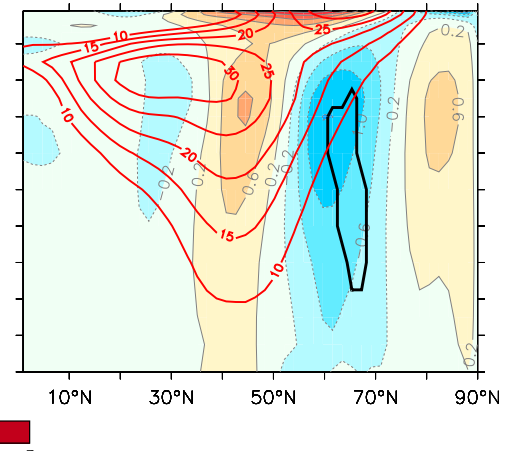

d)

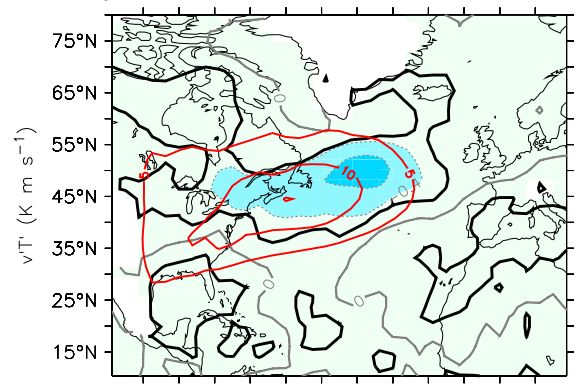

e)

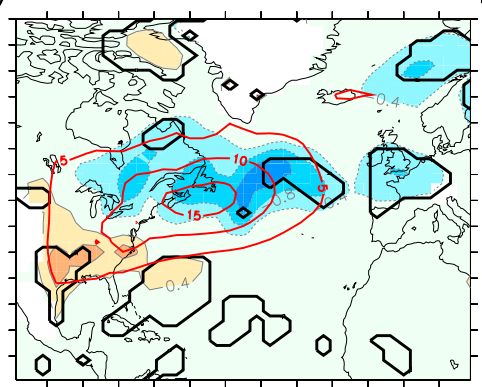

f)

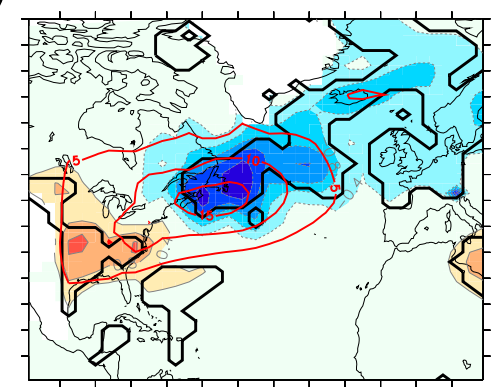

g)

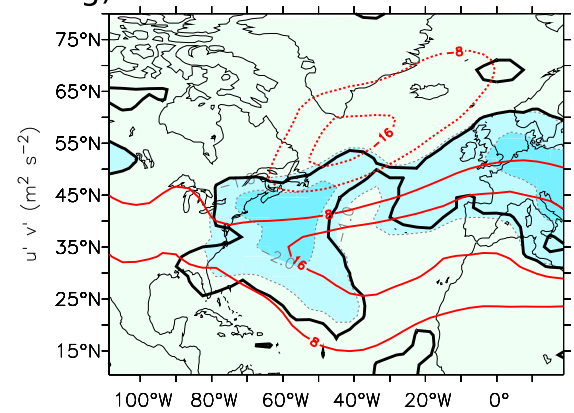

h)

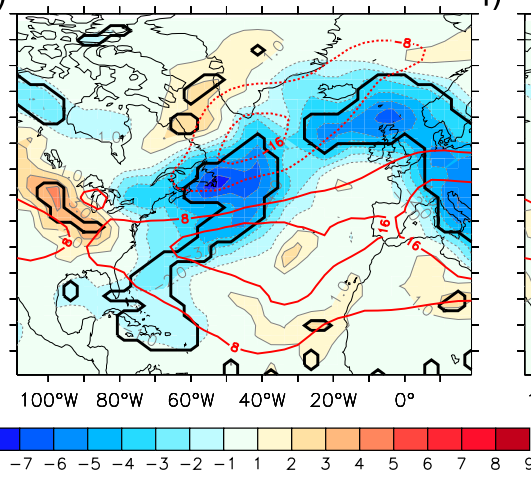

i)

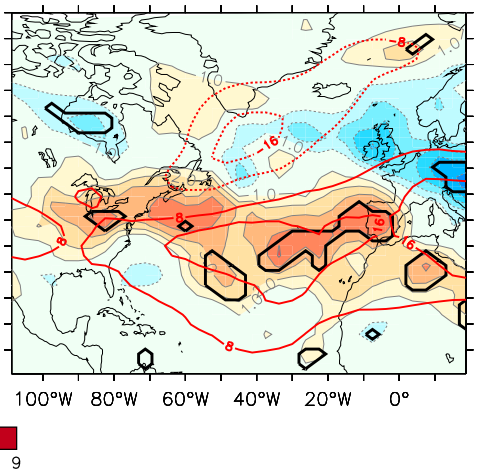

FIG. 9. (a)-(c) Zonal-mean zonal wind $\left(\mathrm{m} \mathrm{s}^{-1}\right)$ over the Atlantic Ocean sector $\left(60^{\circ}-20^{\circ} \mathrm{E}\right)$. (d)-(f) Transients in the meridional eddy heat flux at $850 \mathrm{hPa}\left(v^{\prime} T^{\prime}, \mathrm{K} \mathrm{m} \mathrm{s}^{-1}\right)$. (g)-(i) Transients in the meridional zonal eddy momentum flux at $250 \mathrm{hPa}\left(u^{\prime} v^{\prime}, \mathrm{m}^{2} \mathrm{~s}^{-2}\right)$. For all panels, red contours are the FM climatology and colors in (a),(d),(g) show the regression onto AMOC-PC1 for FM when AMOC leads by 9 yr in IPSL-CM5A-LR. Colors in (b),(e),(h) show the difference Atl ALL $_{-}$CTR for FM and in (c),(f),(i) the difference Atl SST $_{-}$CTR for FM. The black contours indicate significance at the $10 \%$ level.

eddy meridional zonal momentum transport are larger over the Atlantic Ocean (Fig. 9h) with a large decrease simulated farther downstream over Europe, so that in this case there is a large eddy feedback in the upper troposphere. Yet, the anomalous zonal wind over the Atlantic sector in $\mathrm{Atl}_{\mathrm{ALL}}$ is not significant, but it is similar to that of the coupled model: between 1000 and $600 \mathrm{hPa}$, the eddydriven jet is shifted southward, while the core of the upper-troposphere subtropical jet is more intense.

The Atl SST $_{\text {experiment simulates a larger decrease }}$ in the northward meridional heat transport off of
Newfoundland (Fig. 9f), but also a decrease in the Nordic seas and around Iceland, because of the weaker meridional surface temperature gradient over the sea ice edge. The eddy meridional zonal momentum transport is different compared to the other simulations, as it is more intense over a large band between $25^{\circ}$ and $35^{\circ} \mathrm{N}$ in the Atlantic Ocean (Fig. 9i). The resulting zonal wind changes show a dipolar anomaly shifted northward compared to IPSL-CM5A-LR or Atl $\mathrm{ALL}_{\mathrm{LL}}$, so that the eddy-driven jet is amplified at $45^{\circ} \mathrm{N}$ (not significant) and does not shift southward. 
In summary, the experiments $\mathrm{Atl}_{\mathrm{ALL}}$ and $\mathrm{Atl}_{\mathrm{SST}}$ show similar changes induced by the meridional gradient of the lower-tropospheric diabatic warming in the main eddy growth region, as shown by the coupled model. However, the eddy feedback produced by transient meridional momentum transport differs in the upper troposphere. The stratosphere is studied in the following to explain this difference.

\section{f. Stratospheric anomalies}

Omrani et al. (2014) have shown that the coupling between the stratosphere and the troposphere is crucial for the climate impact of the AMO. We now focus on the stratosphere, and investigate whether such coupling plays an active role in our simulations. The time evolution of the daily temperature anomalies over the polar cap $\left(60^{\circ}-90^{\circ} \mathrm{N}\right)$ smoothed with a 30 -day running mean is displayed in Fig. 10. In Fig. 10a, $\mathrm{Atl}_{\mathrm{ALL}}$ shows a warming that reaches $1 \mathrm{~K}$ in the stratosphere. It begins in early January at $10 \mathrm{hPa}$. Then, it extends downward to $200 \mathrm{hPa}$ by February and March. The warming is less significant than in IPSL-CM5A-LR (Fig. 4d), and only reach the $10 \%$ significance level marginally in March. On the other hand, the simulation $\mathrm{Atl}_{\mathrm{SST}}$ (Fig. 10b) shows a cooling in the stratosphere in February. The difference between $\mathrm{Atl}_{\mathrm{ALL}}$ and $\mathrm{Atl}_{\mathrm{SST}}$ (Fig. 10c) clearly shows that the stratospheric warming in $\mathrm{Atl}_{\mathrm{ALL}}$ is significant. The two other simulations Atl $\mathrm{AST}_{\text {SSN }}$ and Atl $\mathrm{AST}-\mathrm{S}_{\text {Sare consis- }}$ tent with Atl $_{\mathrm{SST}}$, with a cooling occurring in February (Fig. S4 in the supplemental material). We conclude that the presence of sea ice anomalies is key for the stratospheric warming seen in $\mathrm{Atl}_{\mathrm{ALL}}$.

To investigate the troposphere-stratosphere interactions, the EP flux due to planetary waves (wavenumbers 1-3), which accounts for most of the wave activity penetrating into the stratosphere (Hartmann et al. 2000), is computed using daily outputs and then smoothed with a 30-day running mean. The EP flux gives the propagation of planetary wave activity into the polar stratosphere, and its divergence results in zonal flow acceleration (Andrews 1985). Figure 11 shows the EP flux with the scaling of Edmon et al. (1980) to better illustrate the EP flux divergence, for the 30-day period centered on 10 February, at the beginning of the stratospheric warming. In the CTR simulation, the planetary waves propagate upward in the troposphere between $40^{\circ}$ and $70^{\circ} \mathrm{N}$ (see Fig. 11a), then some bend equatorward in the upper troposphere at $40^{\circ} \mathrm{N}$, at the core of the subtropical jet. The rest of the wave activity propagates upward into the stratosphere at $55^{\circ} \mathrm{N}$, where it is partly refracted equatorward, and partly absorbed in the polar vortex, above $50 \mathrm{hPa}$. The anomalous EP flux in $\mathrm{Atl}_{\mathrm{ALL}}$ (Fig. 11b) shows an increase in planetary wave
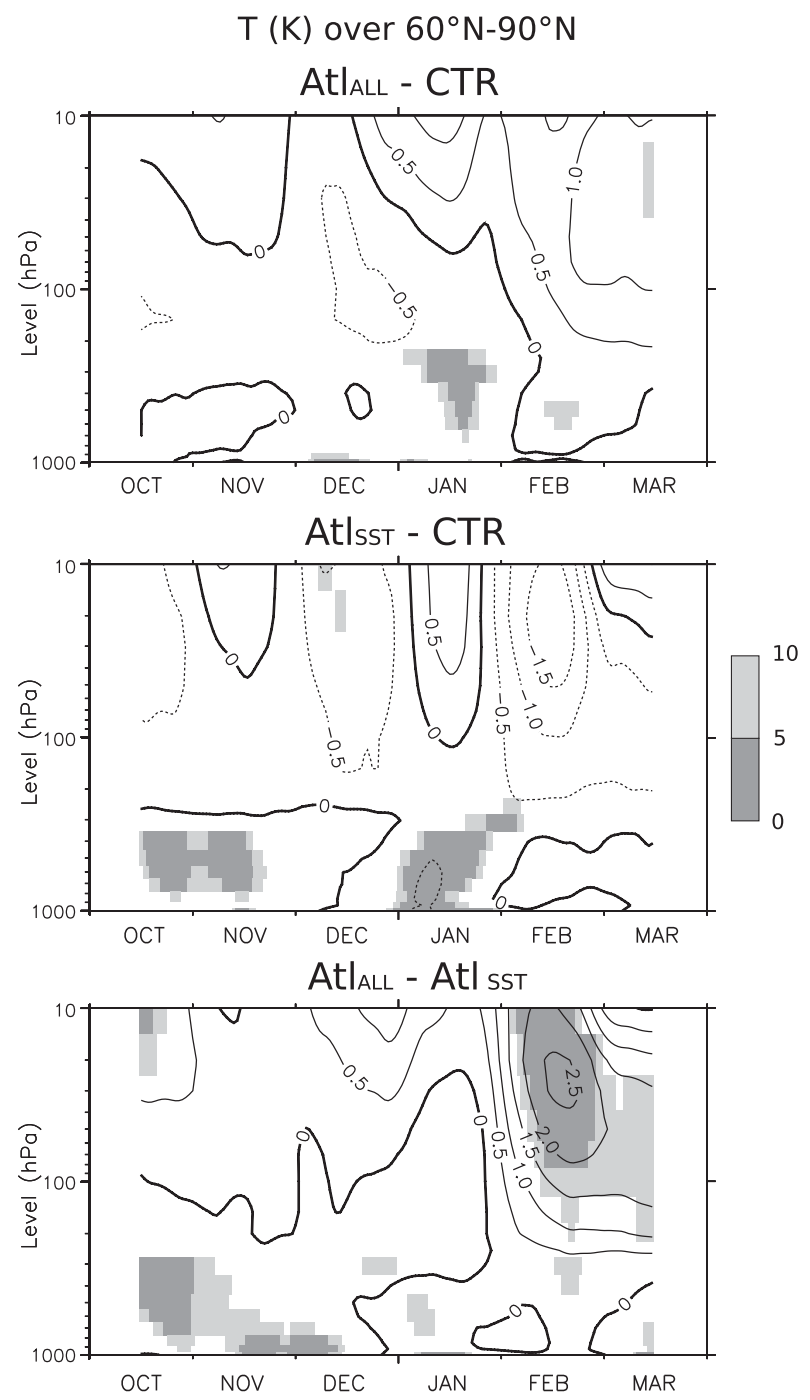

FIG. 10. Temperature $(\mathrm{K})$ averaged over the polar cap $\left(60^{\circ}-90^{\circ} \mathrm{N}\right)$ smoothed with a 30-day running mean for (a) Atl $\mathrm{ALL}_{\mathrm{AL}}-\mathrm{CTR}$, (b) $\mathrm{Atl}_{\mathrm{SST}}-\mathrm{CTR}$, and (c) Atl $\mathrm{ALL}_{\mathrm{AL}}-\mathrm{Atl}_{\mathrm{SST}}$. The gray shading indicates the level of statistical significance.

activity in the troposphere. As a consequence, there is enhanced vertical propagation into the stratosphere between $40^{\circ}$ and $60^{\circ} \mathrm{N}$, as well as more poleward refraction. This leads to an anomalous EP flux convergence in the polar stratosphere, driving a weakening of the polar vortex. The stronger vertical propagation in the stratosphere is linked with a larger wave source at $45^{\circ} \mathrm{N}$ in the troposphere; it could be also due to the changes in static stability or to the weaker vortex itself (Li et al. 2007). The simulation Atl SST $_{\text {SS }}$ shows a similar weakening of the tropospheric waves at higher latitudes, but there is enhanced downward propagation from $40^{\circ}$ to $80^{\circ} \mathrm{N}$, which is expected to increase the polar vortex. 

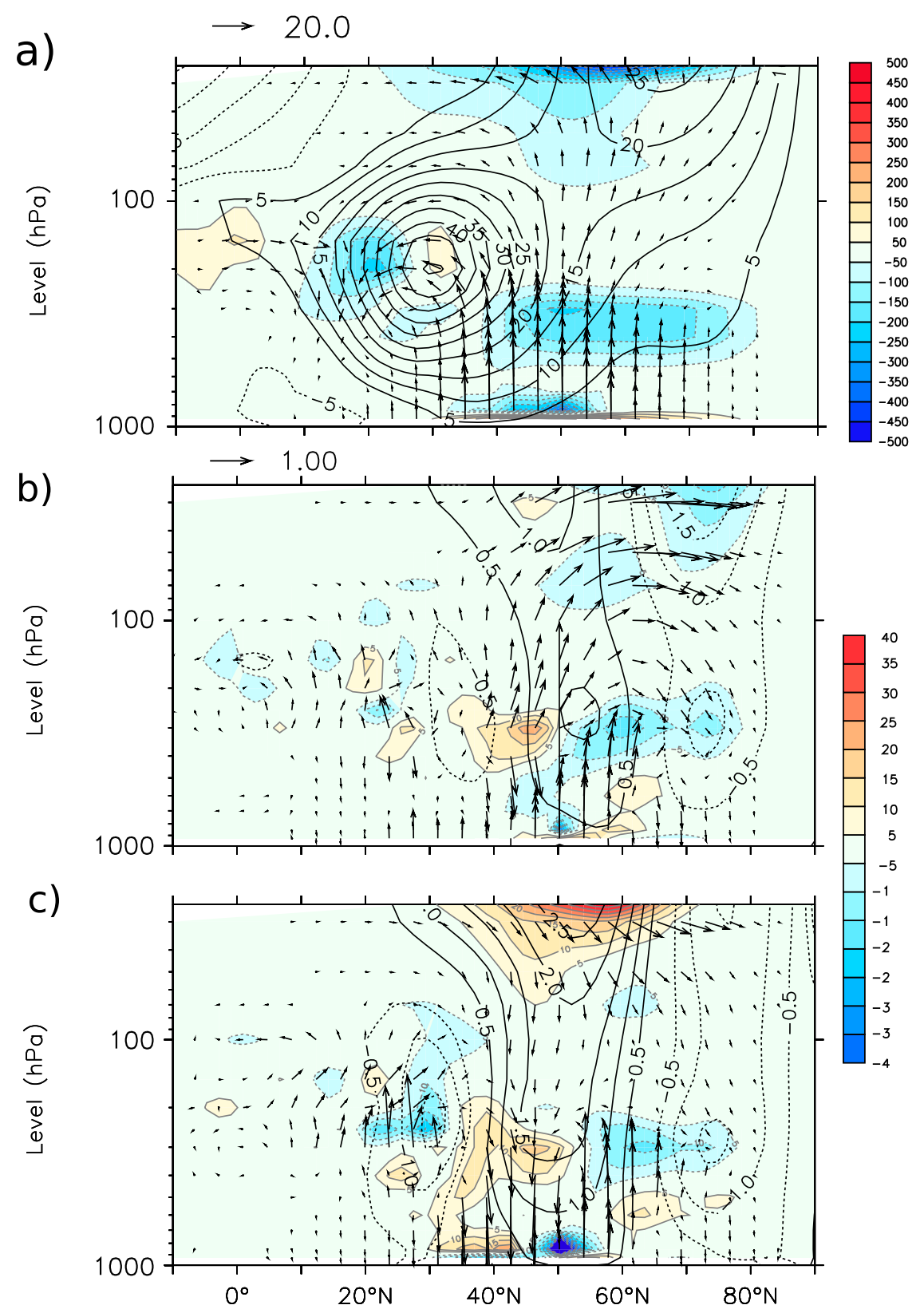

FIG. 11. The EP flux by planetary (zonal wavenumber $k=1-3$ ) waves (arrows, $\mathrm{m}^{2} \mathrm{~s}^{-2}$ ), its divergence (colors, $\mathrm{m} \mathrm{s}^{-2}$ ), and zonal-mean zonal wind (contours, $\mathrm{m} \mathrm{s}^{-1}$ ), for the 30 -day period

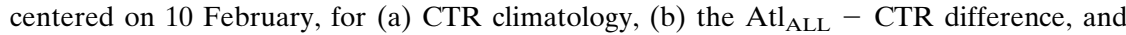

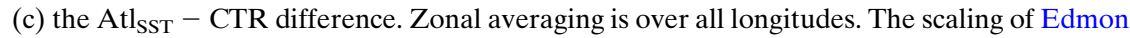
et al. (1980) is used for the EP flux vectors.

The main difference in the tropospheric circulation pattern between $\mathrm{Atl}_{\mathrm{ALL}}$ and Atl $\mathrm{SST}_{\mathrm{SS}}$ on 10 February, at the beginning of the period of strong stratospheric warming, is illustrated by the Z500 (Fig. 12a) and the 100-hPa geopotential height (Z100) anomalies (see Fig. 12b). It reveals a large-scale pattern with a significant Z500 dipole over Eurasia, with positive anomalies over the Urals and western Russia, and negative anomalies over the southern part of central Asia, between the Arabian Peninsula and the Tibetan Plateau. Conversely, a large anticyclonic Z100 anomaly is located north of Bering Strait, while negative anomalies are simulated over the Mediterranean region and central Asia. Such blocking patterns are consistent with upward planetary wave activity 
a)

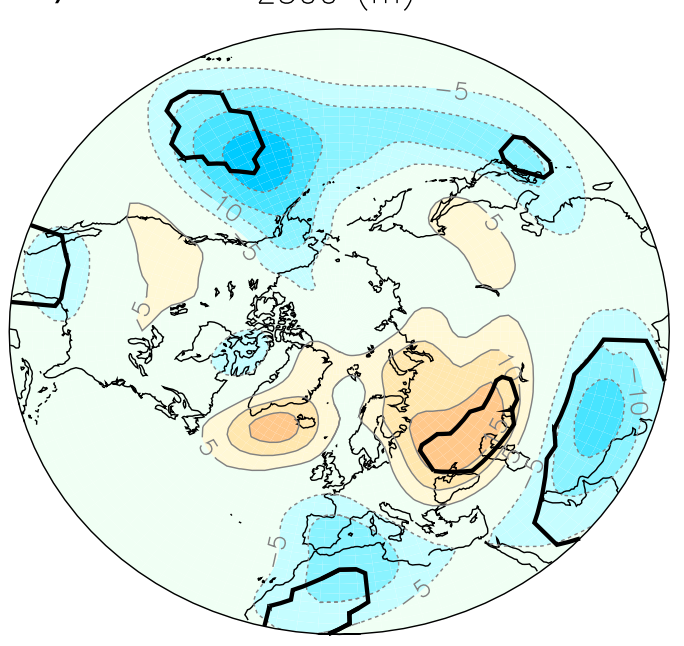

b)

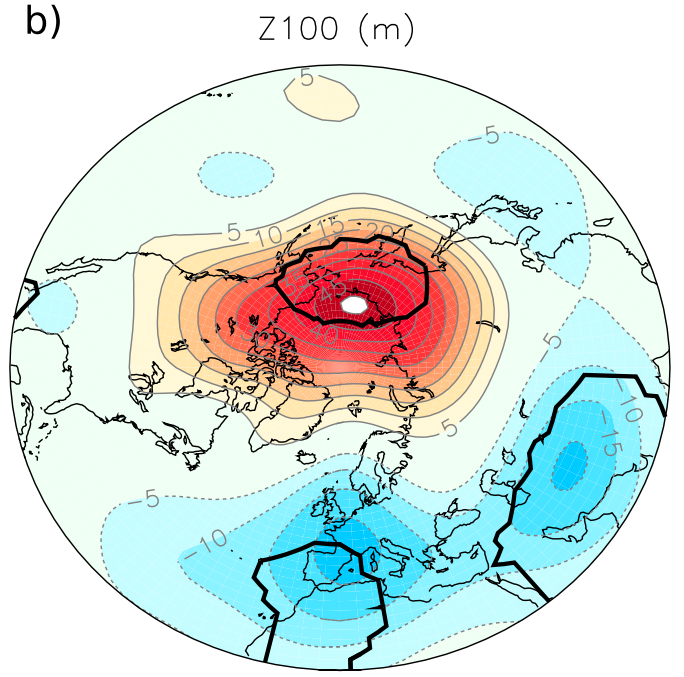

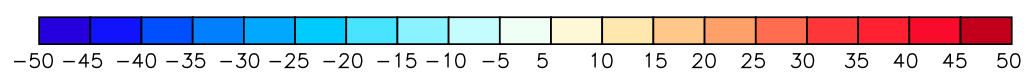

FIG. 12. Response to SIC anomalies on 10 February of (a),(b) Z500 and Z100 (colors and gray contours, m), respectively. The response is given by the difference $\mathrm{Atl}_{\mathrm{ALL}}-\mathrm{Atl} \mathrm{SST}_{\mathrm{SS}}$. The thick black contours indicate significance at the $10 \%$ level.

and have been associated with stratospheric warming in IPSL-CM5A-LR (Vial et al. 2013). This warming of the stratosphere in February may then influence the troposphere, favoring the occurrence of negative NAO events during the following months (Baldwin and Dunkerton 2001), acting as a positive feedback.

\section{Discussion and conclusions}

In the coupled model IPSL-CM5A-LR, an NAO-like atmospheric response to the AMOC was found (GF12). The atmospheric changes are most significant in late winter (FM), $9 \mathrm{yr}$ after an AMOC intensification. Atmospheric response experiments were undertaken to understand the origin of and processes related to the atmospheric response. We designed the experiments to include as boundary forcing the SST and sea ice fingerprint of the AMOC in the North Atlantic, and to distinguish the impact of the SST anomalies in different parts of the North Atlantic.

The simulated atmospheric response to both SST and sea ice anomalies in the Atlantic sector is comparable to that of the coupled model IPSL-CM5A-LR in late winter (FM), which resembles a negative phase of the NAO. However, the tropospheric changes are larger because of the more intense heat flux damping when using prescribed surface oceanic conditions (Barsugli and Battisti 1998). We suggest that the atmospheric response mainly results from a decrease in the lower troposphere baroclinicity over the main transient eddy growth region centered over the Gulf Stream, as found in the coupled run (GF12; Frankignoul et al. 2013). This causes a weakening of eddy meridional heat flux at low levels and a weakening of the storm track activity downstream, which is consistent with a negative phase of the NAO. Furthermore, the stratosphere shows a warming associated with the largest tropospheric changes, in both the coupled and atmosphere-only simulations. Such stratospheric warming is suggested to propagate downward, thereby reinforcing the tropospheric changes a few weeks later and producing a pattern more similar to a negative phase of the Arctic Oscillation, as found by Vial et al. (2013) in IPSL-CM5A.

The simulation using only North Atlantic SST anomalies shows a tropospheric response in FM of the same sign as the coupled model, but the changes are weaker, albeit not significantly so. In the lower troposphere, the eddy feedback is consistent with that in the coupled model, but it is opposite in the upper troposphere. This only leads to small changes of the North Atlantic eddy-driven jet. The stratosphere was also found to be cooler in February, which may contribute to the smaller atmospheric response. To further investigate the atmospheric response to the SST forcing, we performed additional simulations by only prescribing the SST anomalies either over the southern or the northern part of the North Atlantic. Both simulations show results consistent with the simulation using SST-only anomalies in the whole North Atlantic domain, but the response to the warming in the northern part of the 
AMOC fingerprint is larger and more significant than the one due to the concomitant SST anomalies near the Gulf Stream or in the subtropical Atlantic. Hence, the SST anomalies in the subpolar basin seem to have a dominant influence in IPSL-CM5A-LR, as they modify the meridional SST gradient off Newfoundland and the poleward eddy heat flux.

The role of sea ice anomalies was inferred by comparing the simulation driven by both the SST and SIC anomalies and simulations only driven by SST anomalies. If the atmospheric response to boundary forcing was linear, the results would suggest that SST anomalies have the largest influence on the troposphere. The presence of SIC anomalies in IPSL-CM5A-LR in late winter leads to cyclonic geopotential height anomalies over central Asia, consistent with a Rossby wave emanating from the polar North Atlantic and propagating across the Eurasian continent, as described in Honda et al. (2009). We suggest that this anomalous tropospheric circulation warms the lower stratosphere, which acts as a positive feedback, increasing the negative NAO-like tropospheric changes driven by the SST. How the stratospheric anomalies propagate downward is beyond the scope of this study, but similar downward propagation has been found in various studies, even if the dynamical mechanisms are not entirely understood (Haynes et al. 1991; Chen and Robinson 1992; Tanaka and Tokinaga 2002).

The experiments performed here are well adapted to further reveal the causality links and the processes that cannot be unambiguously demonstrated by the statistical analysis of coupled simulations, such as in GF12. However, their applicability must be considered with caution, as the IPSL-CM5A-LR climate model has a large cold bias in the midlatitudes and polar regions, and the sea ice edge is located too far south, so that it is much too close to the storm track location (Dufresne et al. 2013). Such large bias in the mean state implies that the SIC impacts may not be realistic. Furthermore, the AMOC sea ice fingerprint needs to be elucidated: the IPSL-CM5A-LR shows that a cooling and an increased sea ice extent in the Nordic seas is associated with the North Atlantic SST warming, $9 \mathrm{yr}$ after an AMOC intensification, while other models or observations suggest that the sea ice extent in the Nordic seas decreases in phase with the Atlantic SST warming (Mahajan et al. 2011; Zhang and Wang 2013; Allison et al. 2015; Zhang 2015). Therefore, the mechanisms concerning the AMOC signature through sea ice impacts illustrated in this study are likely to be model specific.

Acknowledgments. The research leading to these results has received funding from the European Union
Seventh Framework Programme (FP7 2007-2013) under Grant Agreement n.308299 (NACLIM). We acknowledge financial support from Agence Nationale de la Recherche under the reference ANR 2011 Blanc SIMI 5-6 01401 . This work was granted access to the HPC resources of IDRIS under allocation 010239 made by the Grand Equipement National de Calcul Intensif (GENCI). We thank the reviewers for their constructive comments.

\section{REFERENCES}

Allison, L., E. Hawkins, and T. Woollings, 2015: An event-based approach to understanding decadal fluctuations in the Atlantic meridional overturning circulation. Climate Dyn., 44, 163-190, doi:10.1007/s00382-014-2271-9.

Andrews, D. G., 1985: Wave-mean-flow interaction in the middle atmosphere. Advances in Geophysics, Vol. 28A, Academic Press, 249-275, doi:10.1016/S0065-2687(08)60226-5.

Baldwin, M. P., and T. J. Dunkerton, 2001: Stratospheric harbingers of anomalous weather regimes. Science, 294, 581-584, doi:10.1126/science.1063315.

Barnes, E. A., and L. Polvani, 2013: Response of the midlatitude jets, and of their variability, to increased greenhouse gases in the CMIP5 models. J. Climate, 26, 7117-7135, doi:10.1175/ JCLI-D-12-00536.1.

Barsugli, J. J., and D. S. Battisti, 1998: The basic effects of atmosphere-ocean thermal coupling on midlatitude variability. J. Atmos. Sci. 55, 477-493, doi:10.1175/1520-0469(1998)055<0477: TBEOAO $>2.0 . \mathrm{CO} ; 2$.

Blackmon, M. L., J. M. Wallace, N. C. Lau, and S. L. Mullen, 1977: An observational study of the Northern Hemisphere wintertime circulation. J. Atmos. Sci., 34, 1040-1053, doi:10.1175/ 1520-0469(1977)034<1040:AOSOTN>2.0.CO;2.

Bretherton, C. S., C. Smith, and J. M. Wallace, 1992: An intercomparison of methods for finding coupled patterns in climate data. J. Climate, 5, 541-560, doi:10.1175/ 1520-0442(1992)005<0541:AIOMFF>2.0.CO;2.

Cattiaux, J., B. Quesada, A. Arakélian, F. Codron, R. Vautard, and P. Yiou, 2013: North Atlantic dynamics and European temperature extremes in the IPSL model: Sensitivity to atmospheric resolution. Climate Dyn., 40, 2293-2310, doi:10.1007/ s00382-012-1529-3.

Chen, P., and W. A. Robinson, 1992: Propagation of planetary waves between the troposphere and stratosphere. J. Atmos. Sci., 49, 2533-2545, doi:10.1175/1520-0469(1992)049<2533: POPWBT $>2.0 . \mathrm{CO} ; 2$.

Chylek, P., and G. Lesins, 2008: Multidecadal variability of Atlantic hurricane activity: 1851-2007. J. Geophys. Res., 113, D22106, doi:10.1029/2008JD010036.

Clement, A., K. Bellomo, L. N. Murphy, M. A. Cane, T. Mauritsen, G. Rädel, and B. Stevens, 2015: The Atlantic multidecadal oscillation without a role for ocean circulation. Science, $\mathbf{3 5 0}$, 320-324, doi:10.1126/science.aab3980.

Colin de Verdière, A., and T. Huck, 1999: Baroclinic instability: An oceanic wavemaker for interdecadal variability. J. Phys. Oceanogr., 29, 893-910, doi:10.1175/1520-0485(1999)029<0893: BIAOWF $>2.0 . \mathrm{CO} ; 2$.

Delworth, T. L., and M. E. Mann, 2000: Observed and simulated multidecadal variability in the Northern Hemisphere. Climate Dyn., 16, 661-676, doi:10.1007/s003820000075. 
Deser, C., R. A. Tomas, and S. Peng, 2007: The transient atmospheric circulation response to North Atlantic SST and sea ice anomalies. J. Climate, 20, 4751-4767, doi:10.1175/JCLI4278.1.

Drévillon, M., L. Terray, P. Rogel, and C. Cassou, 2001: Mid latitude Atlantic SST influence on European winter climate variability in the NCEP reanalysis. Climate Dyn., 18, 331-344, doi:10.1007/ s003820100178.

Dufresne, J. L., and Coauthors, 2013: Climate change projections using the IPSL-CM5 Earth system model: From CMIP3 to CMIP5. Climate Dyn., 40, 2123-2165, doi:10.1007/s00382-012-1636-1.

Dunstone, N. J., D. M. Smith, and R. Eade, 2011: Multi-year predictability of the tropical Atlantic atmosphere driven by the high latitude North Atlantic Ocean. Geophys. Res. Lett., 38, L14701, doi:10.1029/2011GL047949.

Edmon, H. J., Jr., B. J. Hoskins, and M. E. McIntyre, 1980: Eliassen-Palm cross sections for the troposphere. J. Atmos. Sci., 37, 2600-2616, doi:10.1175/1520-0469(1980)037<2600: EPCSFT $>2.0 . \mathrm{CO} ; 2$.

Enfield, D. B., A. M. Mestas-Nuñez, and P. J. Trimble, 2001: The Atlantic multidecadal oscillation and its relation to rainfall and river flows in the continental U.S. Geophys. Res. Lett., 28 , 2077-2080, doi:10.1029/2000GL012745.

Escudier, R., J. Mignot, and D. Swingedouw, 2013: A 20-year coupled ocean-sea ice-atmosphere variability mode in the North Atlantic in an AOGCM. Climate Dyn., 40, 619-636, doi:10.1007/s00382-012-1402-4.

Fichefet, T., and M. A. Morales Maqueda, 1999: Modelling the influence of snow accumulation and snow-ice formation on the seasonal cycle of the Antarctic sea-ice cover. Climate Dyn., 15, 251-268, doi:10.1007/s003820050280.

Frankcombe, L. M., H. A. Dijkstra, and A. von der Heydt, 2008: Sub-surface signatures of the Atlantic multidecadal oscillation. Geophys. Res. Lett., 35, L19602, doi:10.1029/ 2008GL034989.

Frankignoul, C., P. Müller, and E. Zorita, 1997: A simple model of the decadal response of the ocean to stochastic wind forcing. J. Phys. Oceanogr., 27, 1533-1546, doi:10.1175/1520-0485(1997)027<1533: ASMOTD $>2.0 . C O ; 2$.

— A. Czaja, and B. L'Heveder, 1998: Air-sea feedback in the North Atlantic and surface boundary conditions for ocean models. J. Climate, 11, 2310-2324, doi:10.1175/1520-0442(1998)011<2310: ASFITN $>2.0 . \mathrm{CO} ; 2$.

_, G. Gastineau, and Y. O. Kwon, 2013: The influence of the AMOC variability on the atmosphere in CCSM3. J. Climate, 26, 9774-9790, doi:10.1175/JCLI-D-12-00862.1.

García-Serrano, J., and C. Frankignoul, 2016: On the feedback of the winter NAO-driven sea ice anomalies. Climate Dyn., doi:10.1007/s00382-015-2922-5, in press.

— _ _ G. Gastineau, and A. de la Cámara, 2015: On the predictability of the winter Euro-Atlantic climate: Lagged influence of autumn Arctic sea ice. J. Climate, 28, 5195-5216, doi:10.1175/JCLI-D-14-00472.1.

Gastineau, G., and C. Frankignoul, 2012: Cold-season atmospheric response to the natural variability of the Atlantic meridional overturning circulation. Climate Dyn., 39, 37-57, doi:10.1007/ s00382-011-1109-y.

— and _ 2015: Influence of the North Atlantic SST variability on the atmospheric circulation during the twentieth century. J. Climate, 28, 1396-1416, doi:10.1175/JCLI-D-14-00424.1.

—, F. D'Andrea, and C. Frankignoul, 2013: Atmospheric response to the North Atlantic Ocean variability on seasonal to decadal time scales. Climate Dyn., 40, 2311-2330, doi:10.1007/ s00382-012-1333-0.
Goldenberg, S. B., C. W. Landsea, A. M. Mestas-Nuñez, and W. M. Gray, 2001: The recent increase in Atlantic hurricane activity: Causes and implications. Science, 293, 474-479, doi:10.1126/ science.1060040.

Hartmann, D. L., J. M. Wallace, V. Limpasuvan, D. W. Thompson, and J. R. Holton, 2000: Can ozone depletion and global warming interact to produce rapid climate change? Proc. Natl. Acad. Sci. USA, 97, 1412-1417, doi:10.1073/pnas.97.4.1412.

Haynes, P. H., M. E. McIntyre, T. G. Shepherd, C. J. Marks, and K. P. Shine, 1991: On the "downward control" of extratropical diabatic circulations by eddy-induced mean zonal forces. J. Atmos. Sci., 48, 651-678, doi:10.1175/1520-0469(1991)048<0651: OTCOED $>2.0 . \mathrm{CO} ; 2$.

Hodson, D. L., R. T. Sutton, C. Cassou, N. Keenlyside, Y. Okumura, and T. Zhou, 2010: Climate impacts of recent multidecadal changes in Atlantic Ocean sea surface temperature: A multimodel comparison. Climate Dyn., 34, 10411058, doi:10.1007/s00382-009-0571-2.

— J. I. Robson, and R. T. Sutton, 2014: An anatomy of the cooling of the North Atlantic Ocean in the 1960s and 1970s. J. Climate, 27, 8229-8243, doi:10.1175/JCLI-D-14-00301.1.

Honda, M., J. Inoue, and S. Yamane, 2009: Influence of low Arctic sea-ice minima on anomalously cold Eurasian winters. Geophys. Res. Lett., 36, L08707, doi:10.1029/2008GL037079.

Hoskins, B. J., and P. J. Valdes, 1990: On the existence of storm-tracks. J. Atmos. Sci., 47, 1854-1864, doi:10.1175/ 1520-0469(1990)047<1854:OTEOST > 2.0.CO;2.

Hourdin, F., and Coauthors, 2013: Impact of the LMDZ atmospheric grid configuration on the climate and sensitivity of the IPSL-CM5A coupled model. Climate Dyn., 40, 2167-2192, doi:10.1007/s00382-012-1411-3.

Ionita, M., G. Lohmann, N. Rimbu, and P. Scholz, 2012: Dominant modes of diurnal temperature range variability over Europe and their relationships with large-scale atmospheric circulation and sea surface temperature anomaly patterns. J. Geophys. Res., 117, D15111, doi:10.1029/2011JD016669.

Jamet, Q., T. Huck, O. Arzel, J. M. Campin, and A. C. de Verdière, 2016: Oceanic control of multidecadal variability in an idealized coupled GCM. Climate Dyn., doi:10.1007/s00382-015-2754-3, in press.

Keenlyside, N. S., M. Latif, J. Jungclaus, L. Kornblueh, and E. Roeckner, 2008: Advancing decadal-scale climate prediction in the North Atlantic sector. Nature, 453, 84-88, doi:10.1038/nature06921.

Kerr, R. A., 2000: A North Atlantic climate pacemaker for the centuries. Science, 288, 1984-1985, doi:10.1126/science.288.5473.1984.

Kilbourne, K. H., T. M. Quinn, R. Webb, T. Guilderson, J. Nyberg, and A. Winter, 2008: Paleoclimate proxy perspective on Caribbean climate since the year 1751: Evidence of cooler temperatures and multidecadal variability. Paleoceanography, 23, PA3220, doi:10.1029/2008PA001598.

King, M. P., M. Hell, and N. Keenlyside, 2015: Investigation of the atmospheric mechanisms related to the autumn sea ice and winter circulation link in the Northern Hemisphere. Climate Dyn., 46, 1185-1195, doi:10.1007/s00382-015-2639-5.

Knight, J. R., R. J. Allan, C. K. Folland, M. Vellinga, and M. E. Mann, 2005: A signature of persistent natural thermohaline circulation cycles in observed climate. Geophys. Res. Lett., 32, L20708, doi:10.1029/2005GL024233.

- C. K. Folland, and A. A. Scaife, 2006: Climate impacts of the Atlantic multidecadal oscillation. Geophys. Res. Lett., 33, L17706, doi:10.1029/2006GL026242.

Knudsen, M. F., M. S. Seidenkrantz, B. H. Jacobsen, and A. Kuijpers, 2011: Tracking the Atlantic Multidecadal 
Oscillation through the last 8,000 years. Nat. Commun., 2, 178, doi:10.1038/ncomms1186.

Krinner, G., and Coauthors, 2005: A dynamic global vegetation model for studies of the coupled atmosphere-biosphere system. Global Biogeochem. Cycles, 19, GB1015, doi:10.1029/ 2003GB002199.

Latif, M., and Coauthors, 2004: Reconstructing, monitoring, and predicting multidecadal-scale changes in the North Atlantic thermohaline circulation with sea surface temperature. J. Climate, 17, 1605-1614, doi:10.1175/1520-0442(2004)017<1605: RMAPMC $>2.0 . \mathrm{CO} ; 2$

L'Hévéder, B., F. Codron, and M. Ghil, 2015: Impact of anomalous northward oceanic heat transport on global climate in a slabocean setting. J. Climate, 28, 2650-2664, doi:10.1175/ JCLI-D-14-00377.1.

Li, Q., H. F. Graf, and M. A. Giorgetta, 2007: Stationary planetary wave propagation in Northern Hemisphere winter? Climatological analysis of the refractive index. Atmos. Chem. Phys., 7, 183-200, doi:10.5194/acp-7-183-2007.

Lohmann, K., and Coauthors, 2014: The role of subpolar deep water formation and Nordic Seas overflows in simulated multidecadal variability of the Atlantic meridional overturning circulation. Ocean Sci., 10, 227-241, doi:10.5194/ os-10-227-2014.

Madec, G., 2008: NEMO ocean engine, version 3.0. Note du Pole de Modélisation 27, Institut Pierre-Simon Laplace, 209 pp. [Available online at http://www.nemo-ocean.eu/content/download/ 5302/31828/file/NEMO_book.pdf.]

Mahajan, S., R. Zhang, and T. L. Delworth, 2011: Impact of the Atlantic meridional overturning circulation (AMOC) on Arctic surface air temperature and sea ice variability. J. Climate, 24, 6573-6581, doi:10.1175/2011JCLI4002.1.

Marini, C., and C. Frankignoul, 2014: An attempt to deconstruct the Atlantic multidecadal oscillation. Climate Dyn., 43, 607625, doi:10.1007/s00382-013-1852-3.

Marti, O., and Coauthors, 2010: Key features of the IPSL ocean atmosphere model and its sensitivity to atmospheric resolution. Climate Dyn., 34, 1-26, doi:10.1007/s00382-009-0640-6.

Matei, D., J. Baehr, J. H. Jungclaus, H. Haak, W. A. Müller, and J. Marotzke, 2012: Multiyear prediction of monthly mean Atlantic meridional overturning circulation at $26.5^{\circ}$ N. Science, 335, 76-79, doi:10.1126/science.1210299.

Mauritzen, C., 1996: Production of dense overflow waters feeding the North Atlantic across the Greenland-Scotland Ridge. Part 1: Evidence for a revised circulation scheme. Deep-Sea Res. I, 43, 769-806, doi:10.1016/0967-0637(96)00037-4.

McCabe, G. J., M. A. Palecki, and J. L. Betancourt, 2004: Pacific and Atlantic Ocean influences on multidecadal drought frequency in the United States. Proc. Natl. Acad. Sci. USA, 101, 4136-4141, doi:10.1073/pnas.0306738101.

Medhaug, I., and T. Furevik, 2011: North Atlantic 20th century multidecadal variability in coupled climate models: Sea surface temperature and ocean overturning circulation. Ocean Sci., 7, 389-404, doi:10.5194/os-7-389-2011.

Mohino, E., S. Janicot, and J. Bader, 2011: Sahel rainfall and decadal to multi-decadal sea surface temperature variability. Climate Dyn., 37, 419-440, doi:10.1007/s00382-010-0867-2.

Msadek, R., K. W. Dixon, T. L. Delworth, and W. Hurlin, 2010: Assessing the predictability of the Atlantic meridional overturning circulation and associated fingerprints. Geophys. Res. Lett., 37, L19608, doi:10.1029/2010GL044517.

Olsen, S. M., B. Hansen, D. Quadfasel, and S. Østerhus, 2008: Observed and modelled stability of overflow across the
Greenland-Scotland ridge. Nature, 455, 519-522, doi:10.1038/ nature 07302 .

Omrani, N. E., N. S. Keenlyside, J. Bader, and E. Manzini, 2014: Stratosphere key for wintertime atmospheric response to warm Atlantic decadal conditions. Climate Dyn., 42, 649-663, doi:10.1007/s00382-013-1860-3.

Ortega, P., J. Mignot, D. Swingedouw, F. Sévellec, and É. Guilyardi, 2015: Reconciling two alternative mechanisms behind bidecadal variability in the North Atlantic. Prog. Oceanogr., 137A, 237-249, doi:10.1016/j.pocean.2015.06.009.

Otterå, O. H., M. Bentsen, H. Drange, and L. Suo, 2010: External forcing as a metronome for Atlantic multidecadal variability. Nat. Geosci., 3, 688-694, doi:10.1038/ngeo955.

Park, S., C. Deser, and M. A. Alexander, 2005: Estimation of the surface heat flux response to sea surface temperature anomalies over the global oceans. J. Climate, 18, 4582-4599, doi:10.1175/JCLI3521.1.

Peings, Y., and G. Magnusdottir, 2014: Forcing of the wintertime atmospheric circulation by the multidecadal fluctuations of the North Atlantic Ocean. Environ. Res. Lett., 9, 034018, doi:10.1088/1748-9326/9/3/034018.

Peng, S., W. A. Robinson, and M. P. Hoerling, 1997: The modeled atmospheric response to midlatitude SST anomalies and its dependence on background circulation states. J. Climate, 10, 971-987, doi:10.1175/1520-0442(1997)010<0971: TMARTM $>2.0 . \mathrm{CO} ; 2$.

— - — , and S. Li, 2003: Mechanisms for the NAO responses to the North Atlantic SST tripole. J. Climate, 16, 1987-2004, doi:10.1175/1520-0442(2003)016<1987:MFTNRT>2.0.CO;2.

Persechino, A., J. Mignot, D. Swingedouw, S. Labetoulle, and E. Guilyardi, 2013: Decadal predictability of the Atlantic meridional overturning circulation and climate in the IPSLCM5A-LR model. Climate Dyn., 40, 2359-2380, doi:10.1007/ s00382-012-1466-1.

Screen, J. A., I. Simmonds, C. Deser, and R. Tomas, 2013: The atmospheric response to three decades of observed Arctic sea ice loss. J. Climate, 26, 1230-1248, doi:10.1175/JCLI-D-12-00063.1.

Seager, R., Y. Kushnir, M. Ting, M. Cane, N. Naik, and J. Miller, 2008: Would advance knowledge of 1930s SSTs have allowed prediction of the Dust Bowl drought? J. Climate, 21, 32613281, doi:10.1175/2007JCLI2134.1.

Smeed, D. A., and Coauthors, 2014: Observed decline of the Atlantic meridional overturning circulation 2004-2012. Ocean Sci., 10, 29-38, doi:10.5194/os-10-29-2014.

Strong, C., G. Magnusdottir, and H. Stern, 2009: Observed feedback between winter sea ice and the North Atlantic Oscillation. J. Climate, 22, 6021-6032, doi:10.1175/2009JCLI3100.1.

Sutton, R. T., and D. L. Hodson, 2005: Atlantic Ocean forcing of North American and European summer climate. Science, 309, 115-118, doi:10.1126/science.1109496.

Tanaka, H. L., and H. Tokinaga, 2002: Baroclinic instability in high latitudes induced by polar vortex: A connection to the Arctic Oscillation. J. Atmos. Sci., 59, 69-82, doi:10.1175/ 1520-0469(2002)059<0069:BIIHLI >2.0.CO;2.

Ting, M., Y. Kushnir, R. Seager, and C. Li, 2011: Robust features of Atlantic multi-decadal variability and its climate impacts. Geophys. Res. Lett., 38, L17705, doi:10.1029/2011GL048712.

,-- , and C. Li, 2014: North Atlantic multidecadal SST oscillation: External forcing versus internal variability. J. Mar. Syst., 133, 27-38, doi:10.1016/j.jmarsys.2013.07.006.

Trenberth, K. E., 1986: An assessment of the impact of transient eddies on the zonal flow during a blocking episode using localized Eliassen-Palm flux diagnostics. J. Atmos. 
Sci., 43, 2070-2087, doi:10.1175/1520-0469(1986)043<2070: AAOTIO $>2.0 . \mathrm{CO} ; 2$.

Vial, J., T. J. Osborn, and F. Lott, 2013: Sudden stratospheric warmings and tropospheric blockings in a multi-century simulation of the IPSL-CM5A coupled climate model. Climate Dyn., 40, 24012414, doi:10.1007/s00382-013-1675-2.

Zhang, L., and C. Wang, 2013: Multidecadal North Atlantic sea surface temperature and Atlantic meridional overturning circulation variability in CMIP5 historical simulations.
J. Geophys. Res. Oceans, 118, 5772-5791, doi:10.1002/ jgrc.20390.

Zhang, R., 2015: Mechanisms for low-frequency variability of summer Arctic sea ice extent. Proc. Natl. Acad. Sci. USA, 112, 4570-4575, doi:10.1073/pnas.1422296112.

—_, and T. L. Delworth, 2006: Impact of Atlantic multidecadal oscillations on India/Sahel rainfall and Atlantic hurricanes. Geophys. Res. Lett., 33, L17712, doi:10.1029/ 2006 GL026267. 